\title{
Changes in sex difference in swimming speed in finalists at FINA World Championships and the Olympic Games from 1992 to 2013
}

Stefanie Wild ${ }^{1}$, Christoph Alexander Rüst ${ }^{1}$, Thomas Rosemann ${ }^{1}$ and Beat Knechtle ${ }^{1,2^{*}}$

\begin{abstract}
Background: This study investigated swimming speeds and sex differences of finalists competing at the Olympic Games (i.e. 624 female and 672 male athletes) and FINA World Championships (i.e. 990 women and 1008 men) between 1992 and 2013.

Methods: Linear, non-linear and multi-level regression models were used to investigate changes in swimming speeds and sex differences for champions and finalists.

Results: Regarding finalists in FINA World Championships and Olympic Games, swimming speed increased linearly in both women and men in all disciplines and race distances. Male world champions' swimming speed remained stable in $200 \mathrm{~m}$ butterfly, $400 \mathrm{~m}, 800 \mathrm{~m}$ and 1,500 m freestyle. Considering women, swimming speed remained unchanged in $50 \mathrm{~m}$ and $400 \mathrm{~m}$ freestyle. In the Olympic Games, swimming speed of male champions remained unchanged in $200 \mathrm{~m}$ breaststroke, $50 \mathrm{~m}, 400 \mathrm{~m}, 800 \mathrm{~m}$ and 1,500 m freestyle. Female Olympic champions' swimming speed remained stable in $100 \mathrm{~m}$ and $200 \mathrm{~m}$ backstroke, $100 \mathrm{~m}$ butterfly, $200 \mathrm{~m}$ individual medley, $50 \mathrm{~m}$ and $200 \mathrm{~m}$ freestyle. Evaluating sex differences between finalists in FINA World Championships, results showed a linear decrease in $100 \mathrm{~m}$ breaststroke and $200 \mathrm{~m}$ butterfly and a non-linear increase in $100 \mathrm{~m}$ backstroke. In finals at the Olympic Games, the sex difference decreased linearly for $100 \mathrm{~m}$ backstroke, $400 \mathrm{~m}$ and $800 \mathrm{~m}$ freestyle. However, a linear increase for $200 \mathrm{~m}$ butterfly can be reported. Considering Olympic and world champions, the sex difference remained stable in all disciplines and race distances.

Conclusion: Swimming speed of the finalists at the Olympic Games and FINA World Championships increased linearly. The top annual female swimmers increased swimming speed rather at longer race distances (i.e. $800 \mathrm{~m}$ and 1,500 m freestyle, $200 \mathrm{~m}$ butterfly, and $400 \mathrm{~m}$ individual medley), whereas the top annual male swimmers increased it rather at shorter race distances (i.e. $100 \mathrm{~m}$ and $200 \mathrm{~m}$ freestyle, $100 \mathrm{~m}$ butterfly, and $100 \mathrm{~m}$ breaststroke). Sex difference in swimming was unchanged in Olympic and world champions. Finalists and champions at the Olympic Games and FINA World Championships reduced the sex difference with increasing race distance.
\end{abstract}

Keywords: Swimming speed, Sex difference

\footnotetext{
* Correspondence: beat.knechtle@hispeed.ch

${ }^{1}$ Institute of General Practice and for Health Services Research, University of

Zurich, Zurich, Switzerland

${ }^{2}$ Gesundheitszentrum St. Gallen, Vadianstrasse 26, 9001 St. Gallen, Switzerland
} 


\section{Background}

In recent years, there have been numerous studies investigating swimming speed trends in different Olympic disciplines [1-3]. Berthelot et al. [1] analyzed 3,263 swimming world records established for all quantifiable official contests since the first Olympic Games. They distinguished an increase in swimming speed until the 1970s, where a plateau in swimming speed was reached. It was hypothesized that the maximum possible physiological sports performance for human species will be reached in one generation, which implies that half of all world records will not be improved more than $0.05 \%$ by 2027 [1]. Nevill et al. [2] investigated whether swimming world records were beginning to plateau in $100 \mathrm{~m}, 200 \mathrm{~m}$ and $400 \mathrm{~m}$ freestyle swimming. They reported a similar plateau effect between the 1980s and 1990s. Notwithstanding, swimming speed increased again by roughly $2 \%$ at the beginning of the $21^{\text {st }}$ century [4]. This unforeseen swimming speed improvement was investigated and reported by several studies [4-6].

Smith et al. [6] analyzed on scientific tools used in physiological and psychological disciplines. They concluded that athletes could be distinguished on the basis of their psychological skills and emotional competencies. Colwin [5] investigated on training processes and how they improved across the years. It was summarized that in any country the future starts with inspired coaches and not the administrators or scientists. Beside physiological, psychological characteristics as well as trainings processes, Berthelot et al. [4] focused on material science in swimming by measuring the impact of the three successive generations of swimsuits on human performance. As outcome of this study three bursts of swimming speed improvements were reported occurring in 2000, 2008 and 2009.

Summarizing the findings from Colwin [5], Smith et al. [6] and Berthelot et al. [4], mainly four factors were identified to explain the unforeseen swimming speed improvements at the beginning of the $21^{\text {st }}$ century: First, the better evaluation of swimmers by physiological parameters, psychological skills, and emotional competencies [6], second, more efficient training processes based on better training control [5], third, deeper pools and more effective 'antiwave' lane ropes [5] and, fourth, new drag-reducing swimsuits [4].

Considering differences between female and male elite athletes, swimming speed remained stable between 1957 and 2006. Interestingly, female athletes improved their swimming speed in $100 \mathrm{~m}, 200 \mathrm{~m}$ and $400 \mathrm{~m}$ freestyle faster than their male counterparts during the 1960s and 1970s, but never outperformed their male counterparts [2]. Between 1991 and 1995, Tanaka et al. [7] reported a

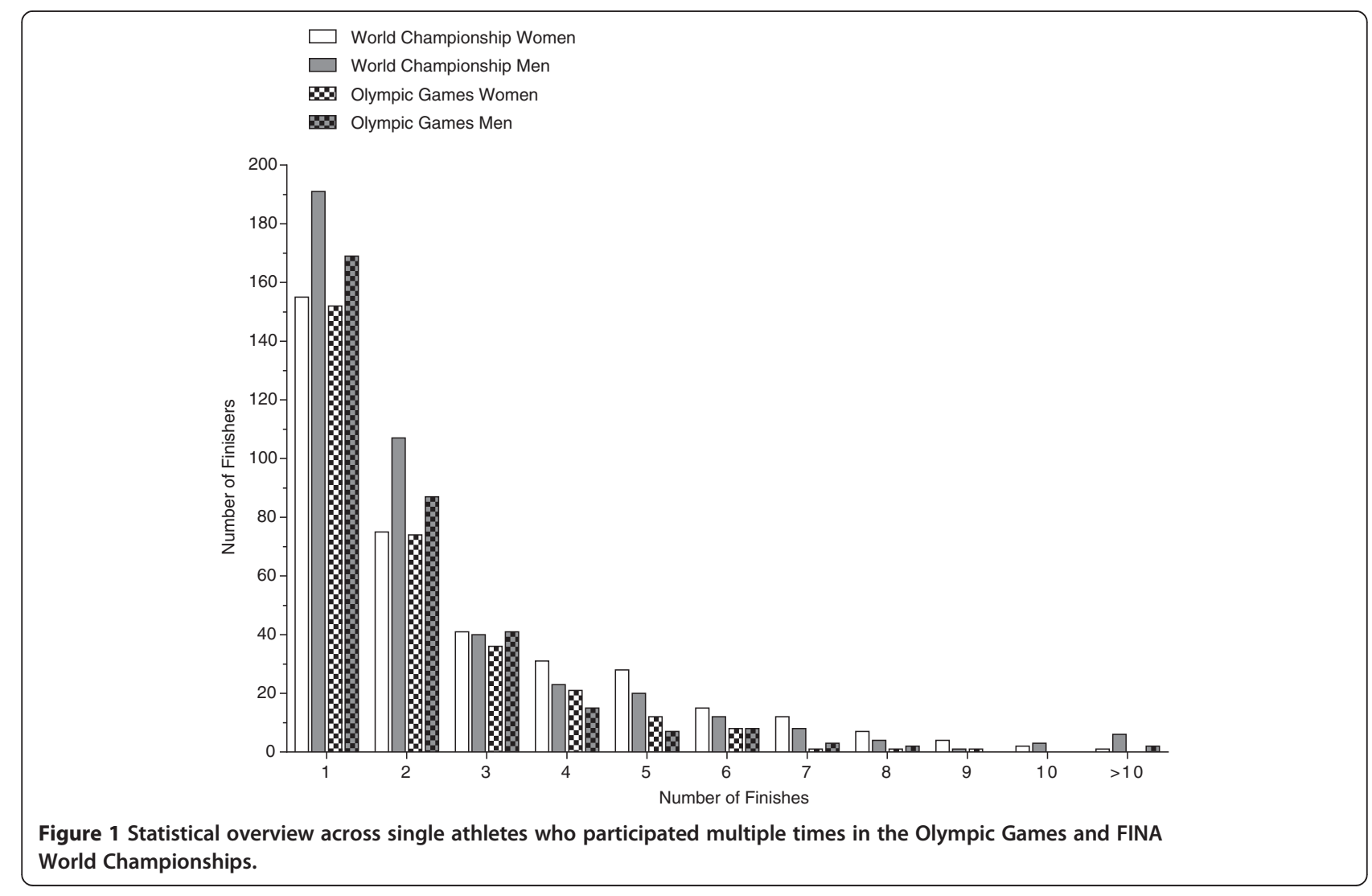




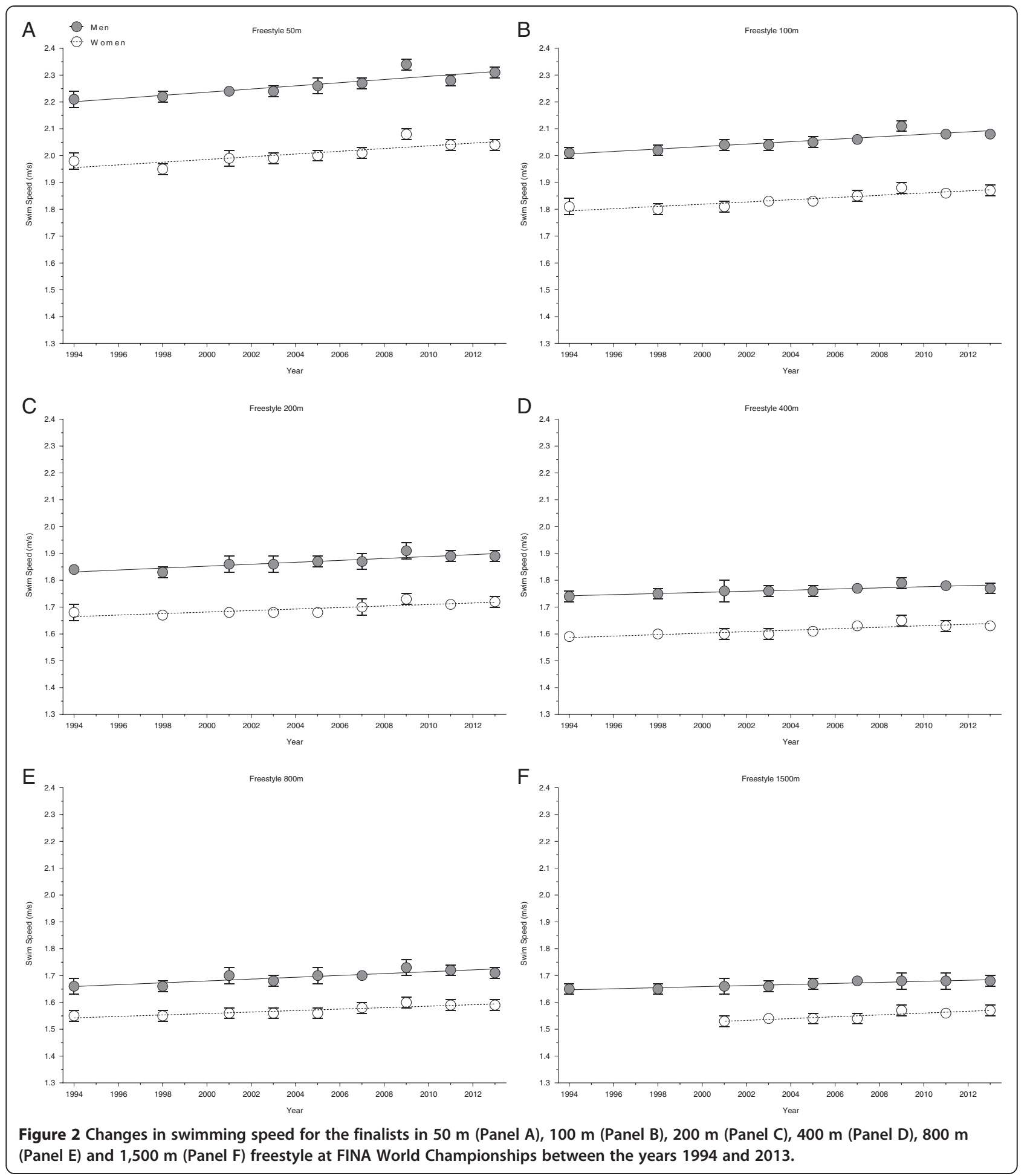

decrease in sex difference with increasing race distance. In detail, for freestyle swimmers, the sex difference in swimming speed decreased from $19 \pm 1 \%$ for $50 \mathrm{~m}$ to $11 \pm$ $1 \%$ for $1,500 \mathrm{~m}$. Despite this development, sex differences between the top-six finalists at each FINA World Championship and the Olympic Games in 100 m freestyle and
$100 \mathrm{~m}$ backstroke swimming increased again between 2000 and 2005 [8]. This led to an overall increase in sex difference between 1981 and 2006. Buhl et al. [9] compared medley and freestyle swimming speeds for national (i.e. top ten elite Swiss athletes) and international swimmers (i.e. top eight FINA World Championship athletes) 

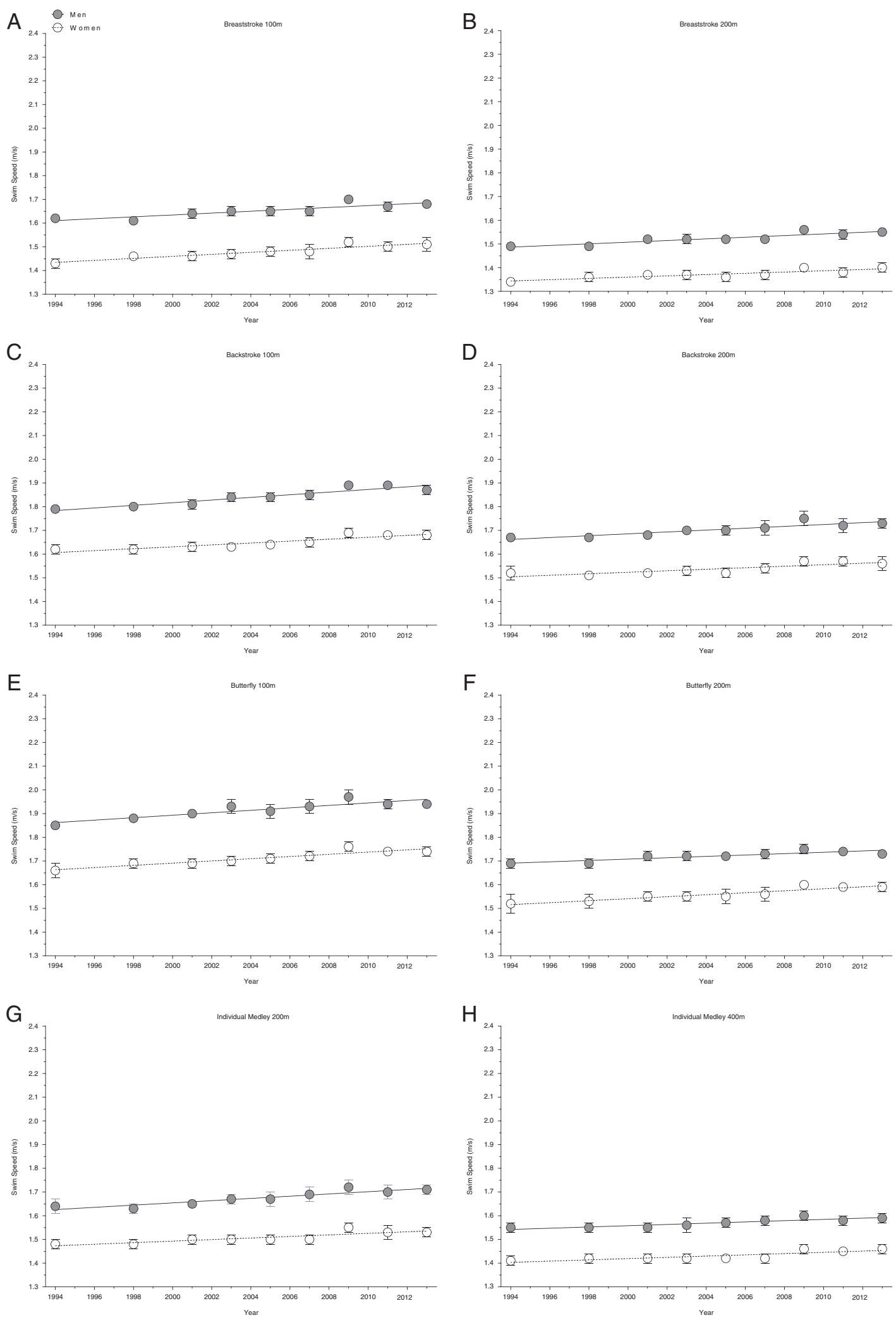

Figure 3 Changes in swimming speed for the finalists in $100 \mathrm{~m}$ breaststroke (Panel A), $200 \mathrm{~m}$ breaststroke (Panel B), $100 \mathrm{~m}$ backstroke (Panel C), $200 \mathrm{~m}$ backstroke (Panel D), $100 \mathrm{~m}$ butterfly (Panel E), $200 \mathrm{~m}$ butterfly (Panel F), $200 \mathrm{~m}$ individual medley (Panel G) and $400 \mathrm{~m}$ individual medley (Panel H) at FINA World Championships between the years 1994 and 2013. 
Table 1 Multi-level regression analysis for changes in swimming speed for the finalists in the FINA World Championships in freestyle, breaststroke, backstroke, butterfly and individual medley with correction for multiple participations and age of the athletes

\begin{tabular}{|c|c|c|c|c|c|c|c|}
\hline Stroke & Sex & Distance (m) & $\beta$ & SE $(\beta)$ & Stand. $\beta$ & $T$ & $p$ \\
\hline \multirow[t]{12}{*}{ Freestyle } & Male & 50 & 0.006 & 0.001 & 0.812 & 10.487 & $<0.001$ \\
\hline & & 100 & 0.005 & 0.000 & 0.803 & 11.396 & $<0.001$ \\
\hline & & 200 & 0.004 & 0.001 & 0.675 & 7.528 & $<0.001$ \\
\hline & & 400 & 0.002 & 0.000 & 0.496 & 4.719 & $<0.001$ \\
\hline & & 800 & 0.004 & 0.001 & 0.651 & 6.958 & $<0.001$ \\
\hline & & 1500 & 0.002 & 0.000 & 0.503 & 4.714 & $<0.001$ \\
\hline & Female & 50 & 0.005 & 0.001 & 0.698 & 8.175 & $<0.001$ \\
\hline & & 100 & 0.004 & 0.001 & 0.749 & 9.154 & $<0.001$ \\
\hline & & 200 & 0.003 & 0.000 & 0.689 & 7.828 & $<0.001$ \\
\hline & & 400 & 0.003 & 0.000 & 0.731 & 8.480 & $<0.001$ \\
\hline & & 800 & 0.002 & 0.000 & 0.590 & 5.925 & $<0.001$ \\
\hline & & 1500 & 0.003 & 0.001 & 0.544 & 4.601 & $<0.001$ \\
\hline \multirow[t]{4}{*}{ Breaststroke } & Male & 100 & 0.003 & 0.000 & 0.814 & 11.718 & $<0.001$ \\
\hline & & 200 & 0.003 & 0.000 & 0.816 & 11.719 & $<0.001$ \\
\hline & Women & 100 & 0.005 & 0.000 & 0.816 & 11.719 & $<0.001$ \\
\hline & & 200 & 0.003 & 0.000 & 0.684 & 7.247 & $<0.001$ \\
\hline \multirow[t]{4}{*}{ Backstroke } & Male & 100 & 0.005 & 0.000 & 0.847 & 12.895 & $<0.001$ \\
\hline & & 200 & 0.004 & 0.000 & 0.704 & 8.243 & $<0.001$ \\
\hline & Women & 100 & 0.005 & 0.000 & 0.797 & 10.525 & $<0.001$ \\
\hline & & 200 & 0.003 & 0.000 & 0.684 & 7.247 & $<0.001$ \\
\hline \multirow[t]{4}{*}{ Butterfly } & Male & 100 & 0.005 & 0.001 & 0.803 & 10.281 & $<0.001$ \\
\hline & & 200 & 0.003 & 0.000 & 0.641 & 6.845 & $<0.001$ \\
\hline & Women & 100 & 0.005 & 0.000 & 0.814 & 11.074 & $<0.001$ \\
\hline & & 200 & 0.004 & 0.001 & 0.707 & 7.997 & $<0.001$ \\
\hline \multirow[t]{4}{*}{ Individual medley } & Male & 200 & 0.005 & 0.001 & 0.749 & 9.189 & $<0.001$ \\
\hline & & 400 & 0.003 & 0.000 & 0.561 & 5.633 & $<0.001$ \\
\hline & Women & 200 & 0.004 & 0.000 & 0.700 & 7.810 & $<0.001$ \\
\hline & & 400 & 0.003 & 0.000 & 0.657 & 7.110 & $<0.001$ \\
\hline
\end{tabular}

between 1994 and 2011. These authors reported that the sex difference for national and international athletes in $400 \mathrm{~m}$ medley as well as freestyle was lower compared to the $200 \mathrm{~m}$ distances. Wolfrum et al. [10] focused on national and international breaststroke and freestyle disciplines and reported a decrease in the sex difference with increasing race distance. Relating to sex difference, Rüst et al. [11] also reported a decrease in sex difference with increasing race distance from $50 \mathrm{~m}$ to $800 \mathrm{~m}$ amongst Swiss elite freestyle swimmers ranked on the Swiss high score list between 2006 and 2010. However, they reported that for $1,500 \mathrm{~m}$ freestyle, the sex difference increased compared to $800 \mathrm{~m}$ freestyle. Buhl et al. [9] compared medley and freestyle swimming speeds for national (i.e. top ten elite Swiss athletes) and international swimmers (i.e. top eight FINA World Championship athletes) between 1994 and 2011. For both, national and international athletes, the sex difference decreased with increasing race distance in both individual medley and freestyle [9].

Beside studies on the swimming speed and sex difference trends in swimming speed at indoor pool competitions, also open-water long-distance races were investigated for the same purpose [12-18]. Vogt et al. [12] studied the sex difference of elite open-water swimmers competing in $10 \mathrm{~km}$ swimming competitions at European Championships, FINA World Championships, World Cup races and the Olympic Games between 2008 and 2012. The study's outcomes showed that the swimming speed remained stable for the best elite female and male athletes. Even compared to other long-distance races (e.g. ultra-running, ultra-cycling) the sex difference in $10 \mathrm{~km}$ swimming with 
Table 2 Change in swimming speed over time for the finalists in the FINA World Championships for women and men

\begin{tabular}{|c|c|c|c|}
\hline \multicolumn{3}{|c|}{ Swim speed $\left(m \cdot s^{-1}\right)$} & \\
\hline Sex & 1994 & 2013 & \\
\hline \multicolumn{3}{|c|}{$50 \mathrm{~m}$ freestyle } & \\
\hline Women & $1.98 \pm 0.03$ & $2.04 \pm 0.02$ & * \\
\hline Men & $2.21 \pm 0.03$ & $2.31 \pm 0.02$ & * \\
\hline \multicolumn{3}{|c|}{$100 \mathrm{~m}$ freestyle } & \\
\hline Women & $1.81 \pm 0.03$ & $1.87 \pm 0.02$ & * \\
\hline Men & $2.01 \pm 0.02$ & $2.08 \pm 0.01$ & * \\
\hline \multicolumn{3}{|c|}{$200 \mathrm{~m}$ freestyle } & \\
\hline Women & $1.68 \pm 0.03$ & $1.72 \pm 0.02$ & * \\
\hline Men & $1.84 \pm 0.01$ & $1.89 \pm 0.02$ & * \\
\hline \multicolumn{3}{|c|}{$400 \mathrm{~m}$ freestyle } & \\
\hline Women & $1.59 \pm 0.01$ & $1.63 \pm 0.01$ & * \\
\hline Men & $1.74 \pm 0.02$ & $1.77 \pm 0.02$ & * \\
\hline \multicolumn{3}{|c|}{$800 \mathrm{~m}$ freestyle } & \\
\hline Women & $1.55 \pm 0.02$ & $1.59 \pm 0.02$ & * \\
\hline Men & $1.66 \pm 0.03$ & $1.71 \pm 0.02$ & * \\
\hline \multicolumn{3}{|c|}{$1,500 \mathrm{~m}$ freestyle } & \\
\hline Women & $1.53 \pm 0.02$ & $1.57 \pm 0.02$ & * \\
\hline Men & $1.65 \pm 0.02$ & $1.68 \pm 0.02$ & * \\
\hline \multicolumn{3}{|c|}{$100 \mathrm{~m}$ breaststroke } & \\
\hline Women & $1.43 \pm 0.02$ & $1.51 \pm 0.03$ & * \\
\hline Men & $1.62 \pm 0.01$ & $1.68 \pm 0.01$ & * \\
\hline \multicolumn{3}{|c|}{$200 \mathrm{~m}$ breaststroke } & \\
\hline Women & $1.34 \pm 0.01$ & $1.40 \pm 0.02$ & * \\
\hline Men & $1.49 \pm 0.01$ & $1.55 \pm 0.01$ & * \\
\hline \multicolumn{3}{|c|}{$100 \mathrm{~m}$ backstroke } & \\
\hline Women & $1.62 \pm 0.02$ & $1.68 \pm 0.02$ & * \\
\hline Men & $1.79 \pm 0.01$ & $1.87 \pm 0.02$ & * \\
\hline \multicolumn{3}{|c|}{$200 \mathrm{~m}$ backstroke } & \\
\hline Women & $1.52 \pm 0.03$ & $1.56 \pm 0.03$ & * \\
\hline Men & $1.67 \pm 0.01$ & $1.73 \pm 0.02$ & * \\
\hline \multicolumn{3}{|c|}{$100 \mathrm{~m}$ butterfly } & \\
\hline Women & $1.66 \pm 0.03$ & $1.74 \pm 0.02$ & * \\
\hline Men & $1.85 \pm 0.01$ & $1.94 \pm 0.01$ & * \\
\hline \multicolumn{3}{|c|}{200 m butterfly } & \\
\hline Women & $1.52 \pm 0.04$ & $1.59 \pm 0.02$ & * \\
\hline Men & $1.69 \pm 0.02$ & $1.73 \pm 0.01$ & * \\
\hline \multicolumn{3}{|c|}{$200 \mathrm{~m}$ individual medley } & \\
\hline Women & $1.48 \pm 0.02$ & $1.53 \pm 0.02$ & * \\
\hline Men & $1.64 \pm 0.03$ & $1.71 \pm 0.02$ & * \\
\hline
\end{tabular}

Table 2 Change in swimming speed over time for the finalists in the FINA World Championships for women and men (Continued)

\begin{tabular}{llll}
\hline & $\mathbf{4 0 0} \boldsymbol{m}$ individual medley & \\
Women & $1.41 \pm 0.02$ & $1.46 \pm 0.02$ & $*$ \\
Men & $1.55 \pm 0.02$ & $1.59 \pm 0.02$ & $*$ \\
\hline Note: ${ }^{*} \mathrm{p}<0.05$. & &
\end{tabular}

7\% was remarkably low. Eichenberger et al. [14] analysed the $26.4 \mathrm{~km}$ 'Marathon Swim' held in Lake Zurich, Switzerland. During the last decade, the sex difference remained stable at $\sim 11.5 \%$. The same authors analyzed the 'Zurich 12 h Swim' between 1996 and 2010, whereby results showed that the annual best swimming speed was not significantly different between male and female athletes [13]. A similar event, namely the $46 \mathrm{~km}$ 'Manhattan Island Marathon Swim' was analyzed for sex difference in swimming speed [15]. The observed time period was from 1983 to 2013. As result these authors stated that the best women were approximately $12-14 \%$ faster than the best men. Rüst et al. investigated on the $36 \mathrm{~km}$ 'Maratona del Golfo Capri-Napoli' [16] and the $32 \mathrm{~km}$ 'Traversée internationale $\mathrm{du}$ lac St-Jean' event [17] regarding sex difference trends in swimming speed. For the 'Maratona del Gofo CapriNapoli' and the 'Traversée international du lac St-Jean' the time period observed was from 1954 to 2013 and from 1955 to 2012, respectively. In conclusion, the fastest women reduced the gap with the fastest men at the $36 \mathrm{~km}$ 'Maratona del Golfo Capri-Napoli' linearly from 40\% to $\sim 5.6 \%$ [16] whereas the sex difference in swimming speed remained unchanged at $8.8 \pm 5.6 \%$ at the $32 \mathrm{~km}$ 'Traversée internationale du lac St-Jean' competition [17]. Zingg et al. [18] investigated on sex difference trends in swimming speed for elite male and female swimmers competing in $5 \mathrm{~km}, 10 \mathrm{~km}$ and $25 \mathrm{~km}$ open-water FINA World Cup races held between 2000 and 2012. These authors reported that the sex difference in swimming remained stable in $5 \mathrm{~km}$, decreased linearly in $10 \mathrm{~km}$ and increased linearly in $25 \mathrm{~km}$.

To the best of our knowledge, no studies investigated swimming speed and sex difference trends in swimming speed in all swimming disciplines held at FINA World Championships and Olympic Games for very recent years. So far, studies have only focused on swimming speed and sex difference trends in swimming speed in a limited range of disciplines and race distances. The present study is the first to focus on a complete evaluation of swimming speed with a focus on sex difference in swimming speed of all indoor swimming events held at FINA World Championships and the Olympic Games.

Therefore, the aim of the present study was to examine the trends in swimming speed and sex difference in swimming speed in all swimming disciplines held at FINA 


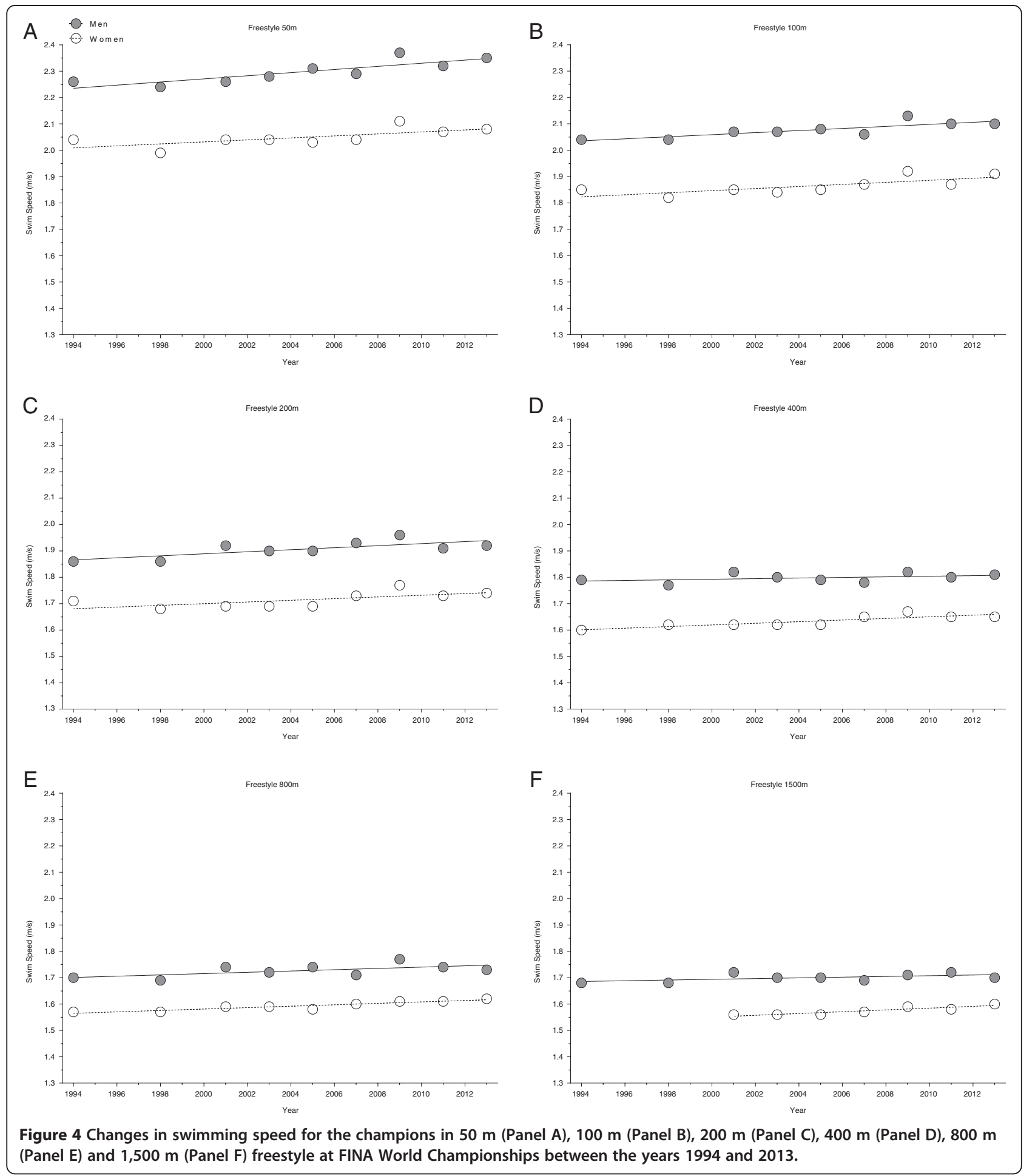

World Championships and the Olympic Games between 1992 and 2013. We hypothesized $(i)$ an improvement in swimming speeds in all disciplines across the years, (ii) a stability of sex differences in swimming speed over the period from 1992 to 2013, and (iii) a decrease in sex difference in swimming speed with increasing race distance.

\section{Methods}

\section{Ethics}

All procedures used in the study were approved by the Institutional Review Board of the Canton of St. Gallen, Switzerland. A waiver of the requirement for informed consent of the participants was granted given the fact 

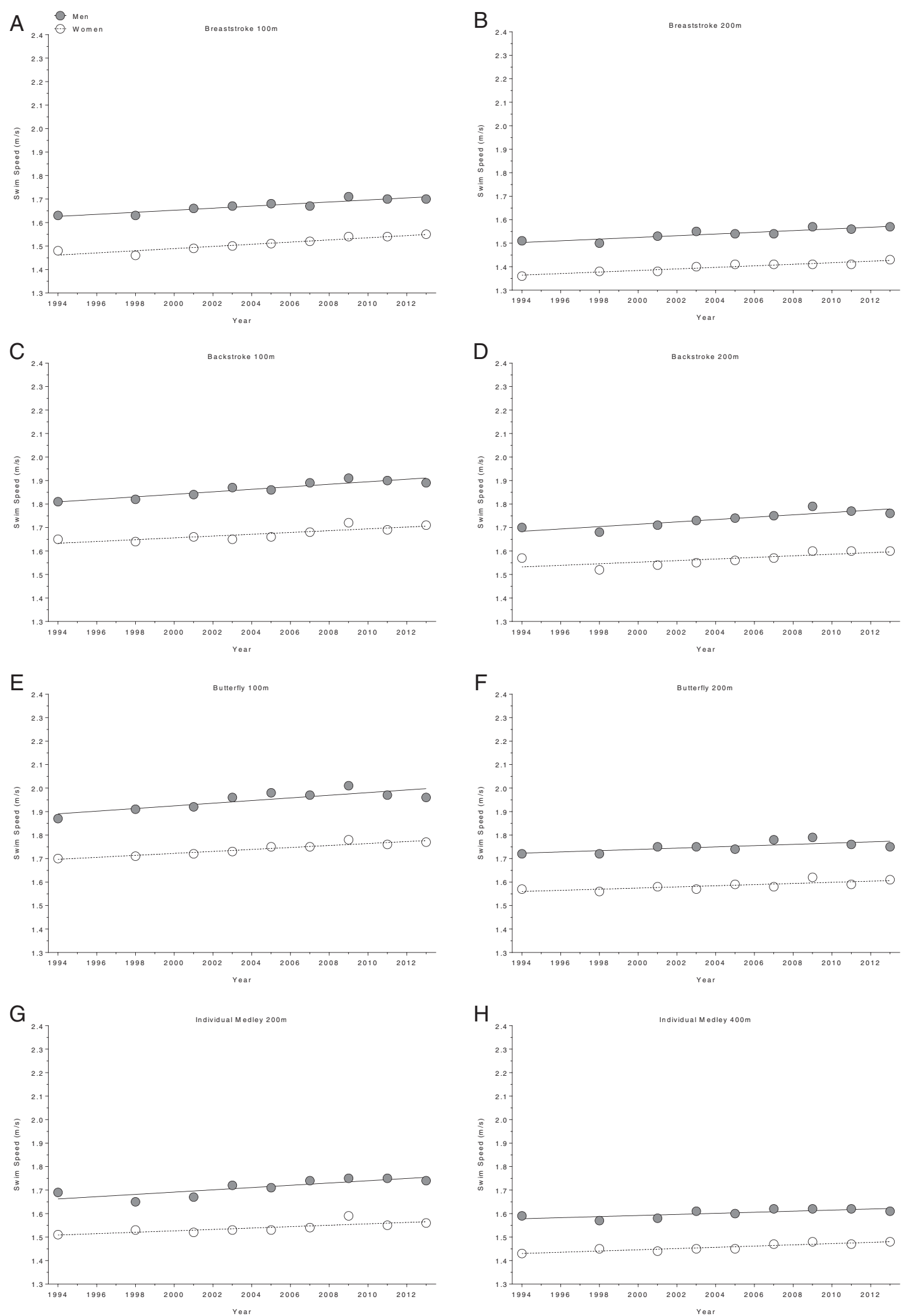

Figure 5 Changes in swimming speed for the champions in $100 \mathrm{~m}$ breaststroke (Panel A), $200 \mathrm{~m}$ breaststroke (Panel B), $100 \mathrm{~m}$ backstroke (Panel C), $200 \mathrm{~m}$ backstroke (Panel D), $100 \mathrm{~m}$ butterfly (Panel E), $200 \mathrm{~m}$ butterfly (Panel F), $200 \mathrm{~m}$ individual medley (Panel G) and $400 \mathrm{~m}$ individual medley (Panel H) at FINA World Championships between the years 1994 and 2013. 
Table 3 Multi-level regression analysis for change in swimming speed for the world champions in freestyle, breaststroke, backstroke, butterfly and individual medley with correction for multiple participations and age of the athletes

\begin{tabular}{|c|c|c|c|c|c|c|c|}
\hline Stroke & Sex & Distance (m) & $\beta$ & SE $(\beta)$ & Stand. $\beta$ & $T$ & $p$ \\
\hline \multirow[t]{12}{*}{ Freestyle } & Male & 50 & 0.006 & 0.001 & 0.846 & 3.997 & 0.007 \\
\hline & & 100 & 0.004 & 0.001 & 0.768 & 3.293 & 0.017 \\
\hline & & 200 & 0.004 & 0.002 & 0.846 & 2.797 & 0.310 \\
\hline & & 400 & 0.001 & 0.001 & 0.259 & 0.672 & 0.527 \\
\hline & & 800 & 0.002 & 0.001 & 0.593 & 1.754 & 0.130 \\
\hline & & 1500 & 0.001 & 0.001 & 0.514 & 1.478 & 0.190 \\
\hline & Female & 50 & 0.004 & 0.002 & 0.693 & 2.206 & 0.070 \\
\hline & & 100 & 0.004 & 0.001 & 0.755 & 2.747 & 0.033 \\
\hline & & 200 & 0.003 & 0.001 & 0.694 & 2.844 & 0.029 \\
\hline & & 400 & 0.005 & 0.002 & 1.282 & 2.335 & 0.058 \\
\hline & & 800 & 0.003 & 0.000 & 0.985 & 7.017 & $<0.001$ \\
\hline & & 1500 & 0.003 & 0.001 & 0.906 & 4.285 & 0.013 \\
\hline \multirow[t]{4}{*}{ Breaststroke } & Male & 100 & 0.005 & 0.001 & 1.126 & 6.187 & 0.001 \\
\hline & & 200 & 0.004 & 0.000 & 0.926 & 9.188 & $<0.001$ \\
\hline & Women & 100 & 0.005 & 0.001 & 0.943 & 7.108 & $<0.001$ \\
\hline & & 200 & 0.004 & 0.000 & 0.926 & 9.188 & $<0.001$ \\
\hline \multirow[t]{4}{*}{ Backstroke } & Male & 100 & 0.006 & 0.001 & 1.003 & 8.373 & $<0.001$ \\
\hline & & 200 & 0.005 & 0.001 & 0.854 & 3.346 & 0.016 \\
\hline & Women & 100 & 0.004 & 0.001 & 0.800 & 3.970 & 0.007 \\
\hline & & 200 & 0.003 & 0.001 & 0.730 & 2.646 & 0.038 \\
\hline \multirow[t]{4}{*}{ Butterfly } & Male & 100 & 0.006 & 0.002 & 0.827 & 3.590 & 0.011 \\
\hline & & 200 & 0.003 & 0.001 & 0.687 & 2.049 & 0.086 \\
\hline & Women & 100 & 0.004 & 0.000 & 0.905 & 9.760 & $<0.001$ \\
\hline & & 200 & 0.003 & 0.001 & 0.687 & 2.049 & 0.086 \\
\hline \multirow[t]{4}{*}{ Individual medley } & Male & 200 & 0.006 & 0.001 & 1.037 & 4.527 & 0.004 \\
\hline & & 400 & 0.002 & 0.001 & 0.761 & 2.697 & 0.036 \\
\hline & Women & 200 & 0.003 & 0.001 & 0.754 & 2.930 & 0.026 \\
\hline & & 400 & 0.003 & 0.001 & 0.902 & 4.589 & 0.004 \\
\hline
\end{tabular}

that the study involved the analysis of publicly available data.

\section{Data sampling and data analysis}

In this study, swimmers competing in the finals of FINA World Championships as well as the Olympic Games between 1992 and 2013 were analyzed and compared regarding change in swimming speed and sex difference. All data was obtained from the publicly accessible FINA and OMEGA web sites $[19,20]$. Only data from the finals were used in order to assure that athletes were only included once per discipline and respective year. The data set used for analysis is based on information from the European Swimming Federation (LEN) rankings database and the results and ranking database from the Belgium, Canadian, Dutch, Faroe, Polish, Portuguese, Slovakian and
Swiss Swimming Federation [21]. Since data before 1992 were incomplete, no race results of competitions held before 1992 were included in the analysis. Additionally, only those race distances were considered which are contested by both women and men.

In total, data was available for 990 women and 1,008 men at FINA World Championships and for 624 women and 672 men at the Olympic Games. Those data originated from 15 finals for each discipline, race distance and sex. The only exception was female individuals in $1,500 \mathrm{~m}$ freestyle where only 7 finals were held during that time period. Prior to analysis, race times were converted to swimming speed $(\mathrm{m} / \mathrm{s})$ using the equation [swimming speed in $\mathrm{m} / \mathrm{s}]=$ [race distance in $\mathrm{m}] /[$ race time in s]. Changes in swimming speed of the winners and all eight finalists were analyzed for every competition, race 
Table 4 Multi-level regression analysis for changes in swimming speed for finalists in the Olympic Games in freestyle, breaststroke, backstroke, butterfly and individual medley with correction for multiple participations and age of the athletes

\begin{tabular}{|c|c|c|c|c|c|c|c|}
\hline Stroke & Sex & Distance (m) & $\beta$ & SE $(\beta)$ & Stand. $\beta$ & $T$ & $p$ \\
\hline \multirow[t]{12}{*}{ Freestyle } & Male & 50 & 0.005 & 0.001 & 0.856 & 9.415 & $<0.001$ \\
\hline & & 100 & 0.004 & 0.000 & 0.841 & 10.247 & $<0.001$ \\
\hline & & 200 & 0.003 & 0.000 & 0.671 & 6.030 & $<0.001$ \\
\hline & & 400 & 0.002 & 0.000 & 0.530 & 4.087 & $<0.001$ \\
\hline & & 800 & 0.002 & 0.000 & 0.537 & 4.245 & $<0.001$ \\
\hline & & 1500 & 0.002 & 0.000 & 0.623 & 5.282 & $<0.001$ \\
\hline & Female & 50 & 0.004 & 0.001 & 0.718 & 6.840 & $<0.001$ \\
\hline & & 100 & 0.003 & 0.000 & 0.800 & 8.683 & $<0.001$ \\
\hline & & 200 & 0.003 & 0.000 & 0.785 & 8.254 & $<0.001$ \\
\hline & & 400 & 0.002 & 0.000 & 0.703 & 6.790 & $<0.001$ \\
\hline & & 800 & 0.002 & 0.000 & 0.620 & 5.832 & $<0.001$ \\
\hline & & 1500 & - & - & - & - & - \\
\hline \multirow[t]{4}{*}{ Breaststroke } & Male & 100 & 0.003 & 0.000 & 0.779 & 7.649 & $<0.001$ \\
\hline & & 200 & 0.003 & 0.000 & 0.801 & 8.939 & $<0.001$ \\
\hline & Women & 100 & 0.003 & 0.000 & 0.799 & 8.689 & $<0.001$ \\
\hline & & 200 & 0.003 & 0.000 & 0.889 & 10.386 & $<0.001$ \\
\hline \multirow[t]{4}{*}{ Backstroke } & Male & 100 & 0.004 & 0.000 & 0.763 & 8.171 & $<0.001$ \\
\hline & & 200 & 0.004 & 0.001 & 0.711 & 6.761 & $<0.001$ \\
\hline & Women & 100 & 0.004 & 0.000 & 0.823 & 9.141 & $<0.001$ \\
\hline & & 200 & 0.003 & 0.001 & 0.662 & 5.902 & $<0.001$ \\
\hline \multirow[t]{4}{*}{ Butterfly } & Male & 100 & 0.004 & 0.000 & 0.863 & 10.782 & $<0.001$ \\
\hline & & 200 & 0.004 & 0.000 & 0.866 & 10.489 & $<0.001$ \\
\hline & Women & 100 & 0.004 & 0.000 & 0.740 & 7.850 & $<0.001$ \\
\hline & & 200 & 0.003 & 0.000 & 0.731 & 7.083 & $<0.001$ \\
\hline \multirow[t]{4}{*}{ Individual medley } & Male & 200 & 0.003 & 0.000 & 0.733 & 7.130 & $<0.001$ \\
\hline & & 400 & 0.003 & 0.001 & 0.624 & 5.447 & $<0.001$ \\
\hline & Women & 200 & 0.004 & 0.001 & 0.779 & 7.723 & $<0.001$ \\
\hline & & 400 & 0.003 & 0.000 & 0.674 & 6.199 & $<0.001$ \\
\hline
\end{tabular}

distance, swim style, age and sex. Additionally, the sex difference between men and women was calculated and analyzed as follows. Sex differences in swimming speed were determined using the equation ([women swimming speed] - [men swimming speed])/[men swimming speed] $\times 100$, for pairs of equally placed athletes (e.g., men's and women's $1^{\text {st }}$ place speeds, men's and women's $2^{\text {nd }}$ place speeds, etc.). The mean and standard deviation were then calculated for all pairs. To facilitate reading, all sex differences were transformed to absolute values before analyzing.

\section{Statistical analysis}

Prior to statistical analysis, each data set was tested for normal distribution using D'Agostino and Pearson omnibus normality test as well as for homogeneity of variances using Levene's Test. Single and multi-level regression analysis investigated changes in swimming speed and age of the finalists. A hierarchical regression model was used to avoid the impact of a cluster-effect on results where a particular athlete from a specific country competed more than once in one year. Regression analyses of swimming speed were corrected for age of athletes to prevent a misinterpretation of the 'age-effect' as a 'time-effect'. Since the change in sex difference in endurance is assumed to be non-linear [22], we additionally calculated the non-linear regression model that fits the data best. When the best-fit model was not a linear but a non-linear polynomial regression, we compared the best-fit non-linear model to the linear model using Akaike's Information Criteria (AIC) and F-test in order to show which model would be the most appropriate to explain the trend of the data. 


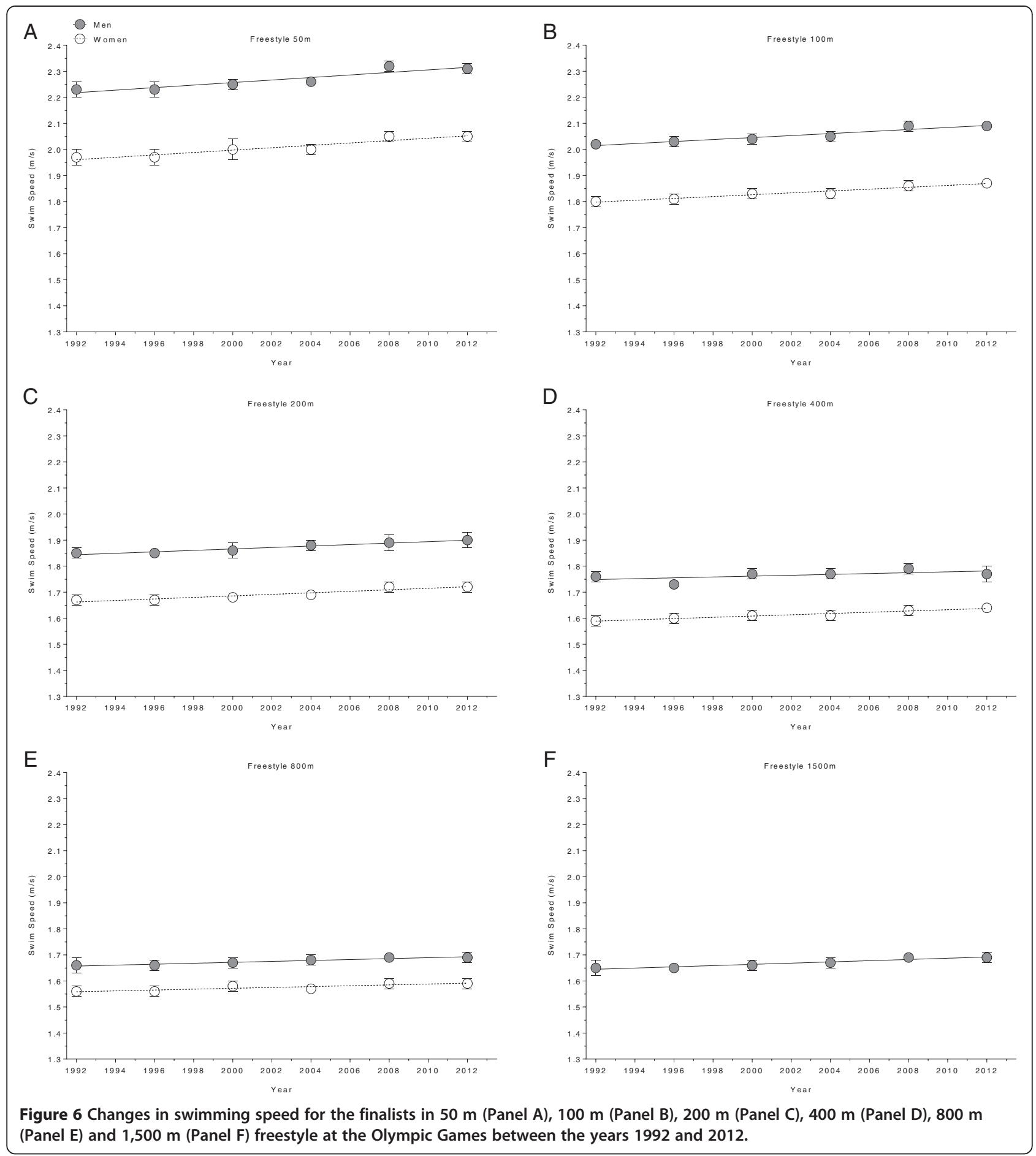

Statistical analyses were performed using IBM SPSS Statistics (Version 21, IBM SPSS, Chicago, IL, USA) and GraphPad Prism (Version 6.01, GraphPad Software, La Jolla, CA, USA). Significance was accepted at $p<0.05$ (two-tailed for $t$-tests). Results were reported in the text and figures as mean \pm standard deviation (SD).

\section{Results}

Multiple participations

In total, data was analysed for 306 female and 334 male individuals at the Olympic Games and 371 female and 415 male individuals at FINA World Championships. In the Olympic Games, 152 women and 169 men participated 


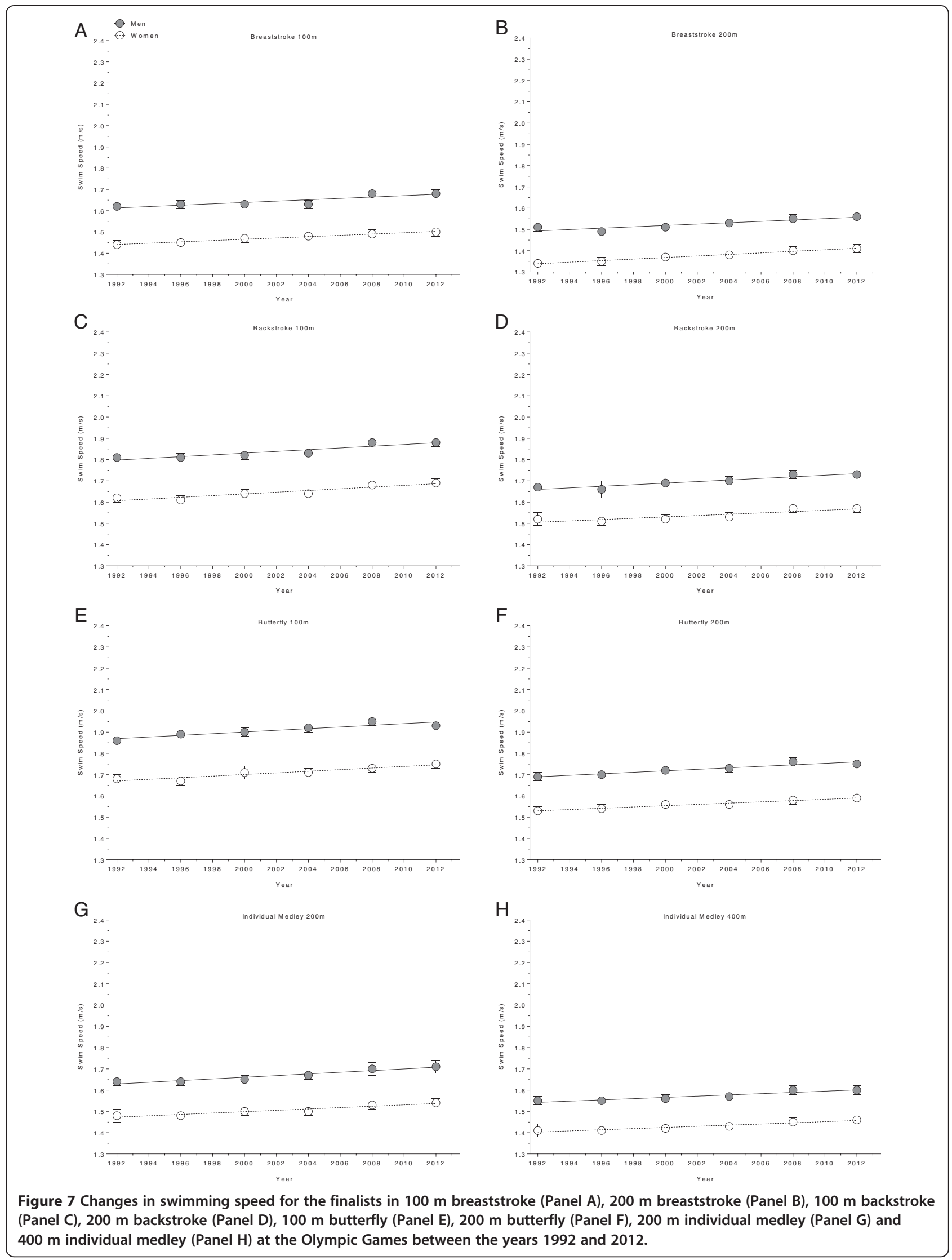


Table 5 Change in swimming speed over time for the finalists in the Olympic Games for women and men

\begin{tabular}{|c|c|c|c|}
\hline \multicolumn{4}{|c|}{ Swim speed $\left(m \cdot \mathrm{s}^{-1}\right)$} \\
\hline Sex & 1992 & 2012 & \\
\hline \multicolumn{4}{|c|}{$50 \mathrm{~m}$ freestyle } \\
\hline Women & $1.97 \pm 0.03$ & $2.05 \pm 0.02$ & * \\
\hline Men & $2.23 \pm 0.03$ & $2.3 \pm 10.02$ & * \\
\hline \multicolumn{4}{|c|}{$100 \mathrm{~m}$ freestyle } \\
\hline Women & $1.80 \pm 0.02$ & $1.87 \pm 0.01$ & * \\
\hline Men & $2.02 \pm 0.01$ & $2.09 \pm 0.01$ & * \\
\hline \multicolumn{4}{|c|}{$200 \mathrm{~m}$ freestyle } \\
\hline Women & $1.67 \pm 0.02$ & $1.72 \pm 0.02$ & * \\
\hline Men & $1.85 \pm 0.02$ & $1.90 \pm 0.03$ & * \\
\hline \multicolumn{4}{|c|}{$400 \mathrm{~m}$ freestyle } \\
\hline Women & $1.59 \pm 0.02$ & $1.64 \pm 0.01$ & * \\
\hline Men & $1.76 \pm 0.02$ & $1.77 \pm 0.03$ & * \\
\hline \multicolumn{4}{|c|}{$800 \mathrm{~m}$ freestyle } \\
\hline Women & $1.56 \pm 0.02$ & $1.59 \pm 0.02$ & * \\
\hline Men & $1.66 \pm 0.03$ & $1.69 \pm 0.02$ & * \\
\hline \multicolumn{4}{|c|}{$1,500 \mathrm{~m}$ freestyle } \\
\hline Women & - & - & \\
\hline Men & $1.65 \pm 0.03$ & $1.69 \pm 0.02$ & * \\
\hline \multicolumn{4}{|c|}{$100 \mathrm{~m}$ breaststroke } \\
\hline Women & $1.44 \pm 0.02$ & $1.50 \pm 0.02$ & * \\
\hline Men & $1.62 \pm 0.01$ & $1.68 \pm 0.02$ & * \\
\hline \multicolumn{4}{|c|}{$200 \mathrm{~m}$ breaststroke } \\
\hline Women & $1.34 \pm 0.02$ & $1.41 \pm 0.02$ & * \\
\hline Men & $1.51 \pm 0.02$ & $1.56 \pm 0.01$ & * \\
\hline \multicolumn{4}{|c|}{$100 \mathrm{~m}$ backstroke } \\
\hline Women & $1.62 \pm 0.02$ & $1.69 \pm 0.02$ & * \\
\hline Men & $1.81 \pm 0.03$ & $1.88 \pm 0.02$ & * \\
\hline \multicolumn{4}{|c|}{$200 \mathrm{~m}$ backstroke } \\
\hline Women & $1.52 \pm 0.03$ & $1.57 \pm 0.02$ & * \\
\hline Men & $1.67 \pm 0.01$ & $1.73 \pm 0.03$ & * \\
\hline \multicolumn{4}{|c|}{$100 \mathrm{~m}$ butterfly } \\
\hline Women & $1.68 \pm 0.02$ & $1.75 \pm 0.02$ & * \\
\hline Men & $1.86 \pm 0.01$ & $1.93 \pm 0.01$ & * \\
\hline \multicolumn{4}{|c|}{200 m butterfly } \\
\hline Women & $1.53 \pm 0.02$ & $1.59 \pm 0.01$ & * \\
\hline Men & $1.69 \pm 0.02$ & $1.75 \pm 0.01$ & * \\
\hline \multicolumn{4}{|c|}{$200 \mathrm{~m}$ individual medley } \\
\hline Women & $1.48 \pm 0.03$ & $1.54 \pm 0.02$ & * \\
\hline Men & $1.64 \pm 0.02$ & $1.71 \pm 0.03$ & * \\
\hline \multicolumn{4}{|c|}{$400 \mathrm{~m}$ individual medley } \\
\hline Women & $1.41 \pm 0.03$ & $1.46 \pm 0.01$ & * \\
\hline Men & $1.55 \pm 0.02$ & $1.60 \pm 0.02$ & * \\
\hline
\end{tabular}

only once, 74 women and 87 men participated twice. Regarding FINA World Championships, 155 women and 191 men competed once, 75 women and 107 men participated twice. One woman and six men competed in FINA World Championships more than ten times. In the Olympic Games, no women participated more than nine times, whereas there were two men which participated more than ten times (Figure 1).

\section{* Changes in swimming speeds over the years in the FINA}

\section{World Championships}

Figures 2 and 3 show the changes in swimming speed for the finalists in the FINA World Championships. In detail, the results for $50 \mathrm{~m}, 100 \mathrm{~m}, 200 \mathrm{~m}, 400 \mathrm{~m}, 800 \mathrm{~m}$ and $1500 \mathrm{~m}$ freestyle are presented in Figure 2 whereas the results for $100 \mathrm{~m}$ and $200 \mathrm{~m}$ breaststroke, $100 \mathrm{~m}$ and $200 \mathrm{~m}$ backstroke, $100 \mathrm{~m}$ and $200 \mathrm{~m}$ butterfly as well as $200 \mathrm{~m}$ and $400 \mathrm{~m}$ individual medley are reflected in Figure 3. Women's and men's swimming speeds increased both linearly for all disciplines and race distances over time (Table 1). In Table 2, the swimming speeds in 1994 and 2013 for both, female and male, finalists at FINA World Championships are presented. Overall, the swimming speeds in each discipline increased * between 1994 and 2013 in both women and men. In Figures 4 and 5, changes in swimming speed for the world * champions between 1994 and 2013 are depicted. Figure 4 focuses on the results for $50 \mathrm{~m}, 100 \mathrm{~m}, 200 \mathrm{~m}, 400 \mathrm{~m}$, $800 \mathrm{~m}$ and $1500 \mathrm{~m}$ freestyle whereas Figure 5 shows the results for $100 \mathrm{~m}$ and $200 \mathrm{~m}$ breaststroke, $100 \mathrm{~m}$ and $200 \mathrm{~m}$ backstroke, $100 \mathrm{~m}$ and $200 \mathrm{~m}$ butterfly as well as $200 \mathrm{~m}$ and $400 \mathrm{~m}$ individual medley. In contrast to the finalists, no significant change in swimming speed for both, female and male world champions could be detected in the investigated disciplines (Table 3). For men, swimming speed remained stable in $200 \mathrm{~m}$ butterfly, $400 \mathrm{~m}$ freestyle, $800 \mathrm{~m}$ freestyle and $1,500 \mathrm{~m}$ freestyle at $1.75 \pm 0.02 \mathrm{~m} / \mathrm{s}$,

$1.8 \pm 0.02 \mathrm{~m} / \mathrm{s}, 1.72 \pm 0.02 \mathrm{~m} / \mathrm{s}$ and $1.7 \pm 0.02 \mathrm{~m} / \mathrm{s}$, respect-

ively. For female world champions, swimming speed remained unchanged in $50 \mathrm{~m}$ freestyle and $400 \mathrm{~m}$ freestyle * at $2.05 \pm 0.03 \mathrm{~m} / \mathrm{s}$ and at $1.63 \pm 0.02 \mathrm{~m} / \mathrm{s}$, respectively.

* However, in $200 \mathrm{~m}$ backstroke, female world champions' swimming speed increased non-linearly, whereas the speed of their male counterparts increased linearly. This non-linear increase was best described with a polynomial $4^{\text {th }}$ degree. In the remaining disciplines swimming speeds of female and male world champions increased linearly over time (Table 3).

\section{Changes in swimming speeds over the years in the Olympic Games}

Similar to the FINA World Championships, swimming speed increased significantly and linearly for female and male finalists in the Olympic Games between 1992 and 
Table 6 Multi-level regression analysis for change in swimming speed for the Olympic Champions in freestyle, breaststroke, backstroke, butterfly and individual medley with correction for multiple participations and age of the athletes

\begin{tabular}{|c|c|c|c|c|c|c|c|}
\hline Stroke & Sex & Distance (m) & $\beta$ & SE $(\beta)$ & Stand. $\beta$ & $T$ & $p$ \\
\hline \multirow[t]{12}{*}{ Freestyle } & Male & 50 & 0.004 & 0.001 & 0.826 & 2.862 & 0.064 \\
\hline & & 100 & 0.004 & 0.001 & 0.909 & 3.496 & 0.040 \\
\hline & & 200 & 0.004 & 0.001 & 0.923 & 4.636 & 0.019 \\
\hline & & 400 & 0.003 & 0.001 & 0.847 & 2.710 & 0.073 \\
\hline & & 800 & 0.001 & 0.001 & 0.483 & 1.083 & 0.358 \\
\hline & & 1500 & 0.002 & 0.001 & 0.898 & 2.561 & 0.083 \\
\hline & Female & 50 & 0.004 & 0.001 & 0.884 & 2.822 & 0.067 \\
\hline & & 100 & 0.003 & 0.000 & 0.914 & 8.164 & 0.004 \\
\hline & & 200 & 0.003 & 0.001 & 0.737 & 2.468 & 0.090 \\
\hline & & 400 & 0.002 & 0.000 & 1.010 & 4.756 & 0.018 \\
\hline & & 800 & 0.002 & 0.001 & 0.891 & 3.354 & 0.044 \\
\hline & & 1500 & - & - & - & - & - \\
\hline \multirow[t]{4}{*}{ Breaststroke } & Male & 100 & 0.003 & 0.001 & 0.758 & 5.260 & 0.013 \\
\hline & & 200 & 0.003 & 0.001 & 0.798 & 2.410 & 0.095 \\
\hline & Women & 100 & 0.003 & 0.000 & 1.003 & 8.998 & 0.003 \\
\hline & & 200 & 0.004 & 0.001 & 1.053 & 3.885 & 0.030 \\
\hline \multirow[t]{4}{*}{ Backstroke } & Male & 100 & 0.003 & 0.001 & 0.769 & 4.159 & 0.025 \\
\hline & & 200 & 0.004 & 0.001 & 0.961 & 6.540 & 0.007 \\
\hline & Women & 100 & 0.003 & 0.001 & 0.839 & 2.966 & 0.059 \\
\hline & & 200 & 0.002 & 0.001 & 0.684 & 1.604 & 0.207 \\
\hline \multirow[t]{4}{*}{ Butterfly } & Male & 100 & 0.004 & 0.001 & 0.844 & 4.513 & 0.020 \\
\hline & & 200 & 0.004 & 0.001 & 1.030 & 3.669 & 0.035 \\
\hline & Women & 100 & 0.004 & 0.002 & 0.778 & 2.057 & 0.132 \\
\hline & & 200 & 0.003 & 0.001 & 0.958 & 5.700 & 0.011 \\
\hline \multirow[t]{4}{*}{ Individual medley } & Male & 200 & 0.005 & 0.001 & 0.956 & 6.424 & 0.008 \\
\hline & & 400 & 0.004 & 0.001 & 0.962 & 5.072 & 0.015 \\
\hline & Women & 200 & 0.002 & 0.001 & 0.500 & 2.025 & 0.136 \\
\hline & & 400 & 0.002 & 0.000 & 0.696 & 6.724 & 0.007 \\
\hline
\end{tabular}

2012 (Table 4). Further, Figures 6 and 7 represent the swimming speed over the years for $50 \mathrm{~m}$ freestyle, $100 \mathrm{~m}$ freestyle, $200 \mathrm{~m}$ freestyle, $400 \mathrm{~m}$ freestyle, $800 \mathrm{~m}$ freestyle, $1500 \mathrm{~m}$ freestyle and $100 \mathrm{~m}$ breaststroke, $200 \mathrm{~m}$ breaststroke, $100 \mathrm{~m}$ backstroke, $200 \mathrm{~m}$ backstroke, $100 \mathrm{~m}$ butterfly, $200 \mathrm{~m}$ butterfly, $200 \mathrm{~m}$ individual medley, $400 \mathrm{~m}$ individual medley, respectively. The corresponding numbers to these disciplines and distances are listed in Table 5 . A comparison solely between Olympic champions revealed a slightly different result. Women's swimming speed remained stable in $100 \mathrm{~m}$ backstroke with $1.67 \pm$ $0.03 \mathrm{~m} / \mathrm{s}, 200 \mathrm{~m}$ backstroke with $1.58 \pm 0.02 \mathrm{~m} / \mathrm{s}, 100 \mathrm{~m}$ butterfly with $1.74 \pm 0.04 \mathrm{~m} / \mathrm{s}, 200 \mathrm{~m}$ individual medley with $1.53 \pm 0.03 \mathrm{~m} / \mathrm{s}, 50 \mathrm{~m}$ freestyle with $2.05 \pm 0.03 \mathrm{~m} / \mathrm{s}$ and $200 \mathrm{~m}$ freestyle with $1.71 \pm 0.03 \mathrm{~m} / \mathrm{s}$, respectively
(Table 6). For men, swimming speed remained unchanged in $200 \mathrm{~m}$ breaststroke with $1.55 \pm 0.02 \mathrm{~m} / \mathrm{s}, 50 \mathrm{~m}$ freestyle with $2.3 \pm 0.04 \mathrm{~m} / \mathrm{s}, 400 \mathrm{~m}$ freestyle with $1.79 \pm 0.02 \mathrm{~m} / \mathrm{s}$, $800 \mathrm{~m}$ freestyle with $1.7 \pm 0.01 \mathrm{~m} / \mathrm{s}$ and $1,500 \mathrm{~m}$ freestyle with $1.7 \pm 0.02 \mathrm{~m} / \mathrm{s}$ (Table 6). In the remaining disciplines, female and male Olympic champions' swimming speed increased linearly over time, when corrected for multiple participation and age of athletes (Table 6). Figures 8 and 9 show these swimming speed trends in the time period between 1992 and 2012. In detail, the results for $50 \mathrm{~m}$, $100 \mathrm{~m}, 200 \mathrm{~m}, 400 \mathrm{~m}, 800 \mathrm{~m}$ and $1500 \mathrm{~m}$ freestyle are depicted in Figure 8 whereas Figure 9 shows the results for $100 \mathrm{~m}$ and $200 \mathrm{~m}$ breaststroke, $100 \mathrm{~m}$ and $200 \mathrm{~m}$ backstroke, $100 \mathrm{~m}$ and $200 \mathrm{~m}$ butterfly as well as $200 \mathrm{~m}$ and $400 \mathrm{~m}$ individual medley. 


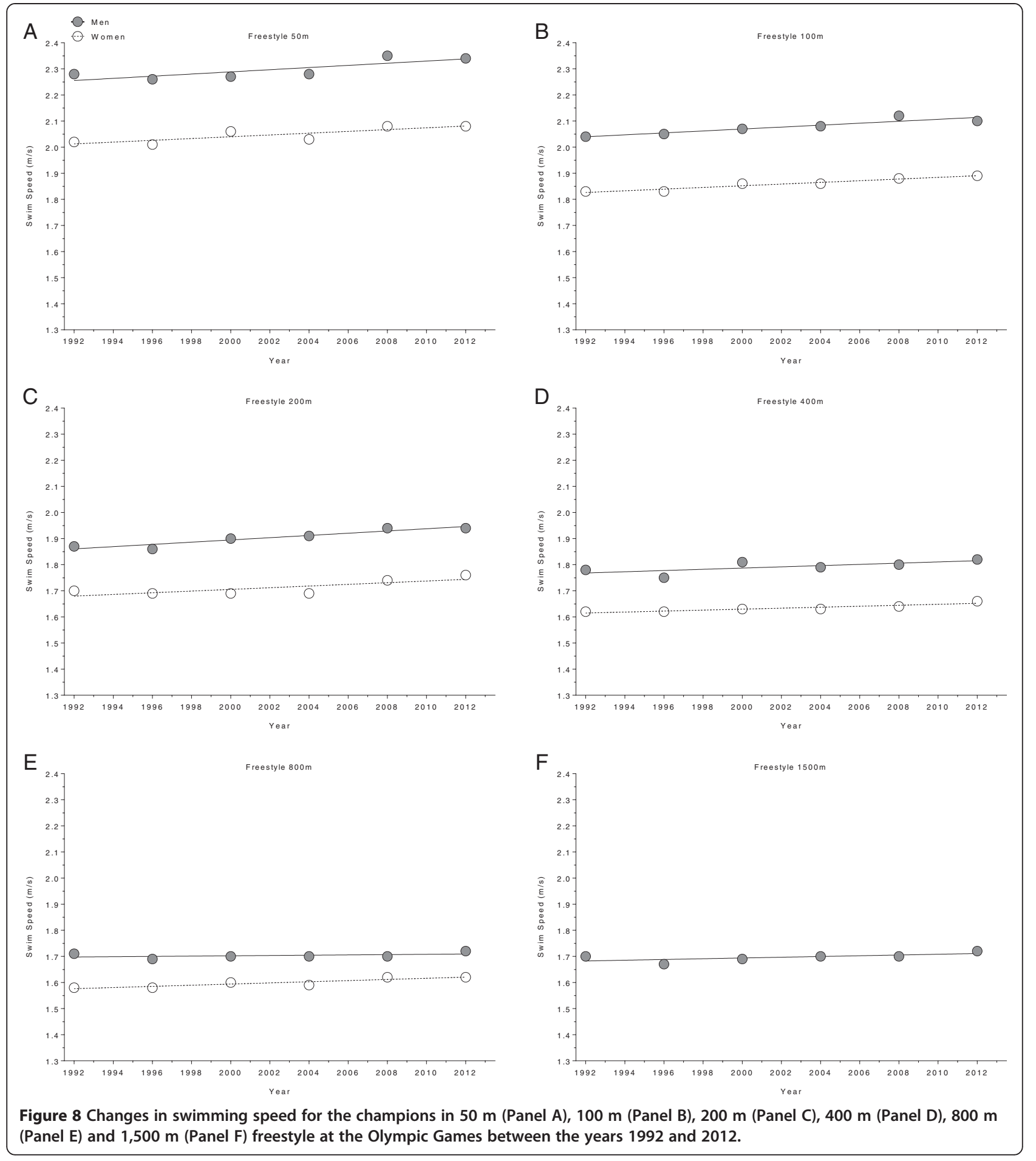

Changes in sex differences over the years in FINA World Championships

Figures 10 and 11 show the changes in sex difference for the finalists in FINA World Championships held between 1994 and 2013. The distribution of the results for the various disciplines and distances is as follows. Results for $50 \mathrm{~m}, 100 \mathrm{~m}, 200 \mathrm{~m}, 400 \mathrm{~m}$ and $800 \mathrm{~m}$ freestyle are depicted in Figure 10. Results for $100 \mathrm{~m}$ breaststroke, $200 \mathrm{~m}$ breaststroke, $100 \mathrm{~m}$ backstroke, $200 \mathrm{~m}$ backstroke, $100 \mathrm{~m}$ butterfly, $200 \mathrm{~m}$ butterfly, $200 \mathrm{~m}$ individual medley and $400 \mathrm{~m}$ individual medley are shown in Figure 11. In $100 \mathrm{~m}$ breaststroke and $200 \mathrm{~m}$ butterfly the sex differences decreased linearly over the years (Table 7). The corresponding numbers are $11.7 \pm 0.95 \%$ to $9.83 \pm 0.8 \%$ and 

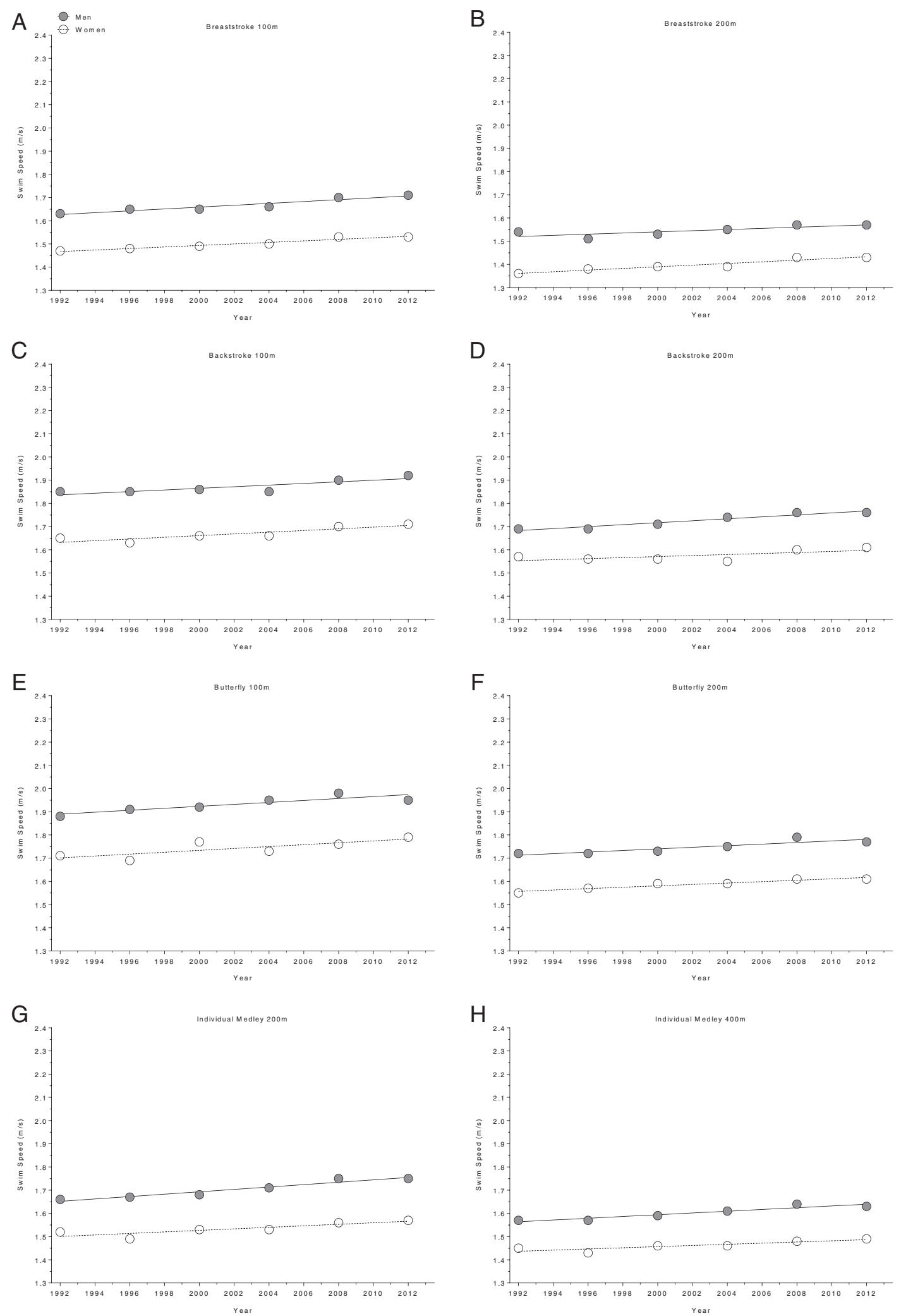

Figure 9 Changes in swimming speed for the champions in $100 \mathrm{~m}$ breaststroke (Panel A), $200 \mathrm{~m}$ breaststroke (Panel B), $100 \mathrm{~m}$ backstroke (Panel C), $200 \mathrm{~m}$ backstroke (Panel D), $100 \mathrm{~m}$ butterfly (Panel E), $200 \mathrm{~m}$ butterfly (Panel F), $200 \mathrm{~m}$ individual medley (Panel G) and $400 \mathrm{~m}$ individual medley (Panel H) at the Olympic Games between the years 1992 and 2012. 


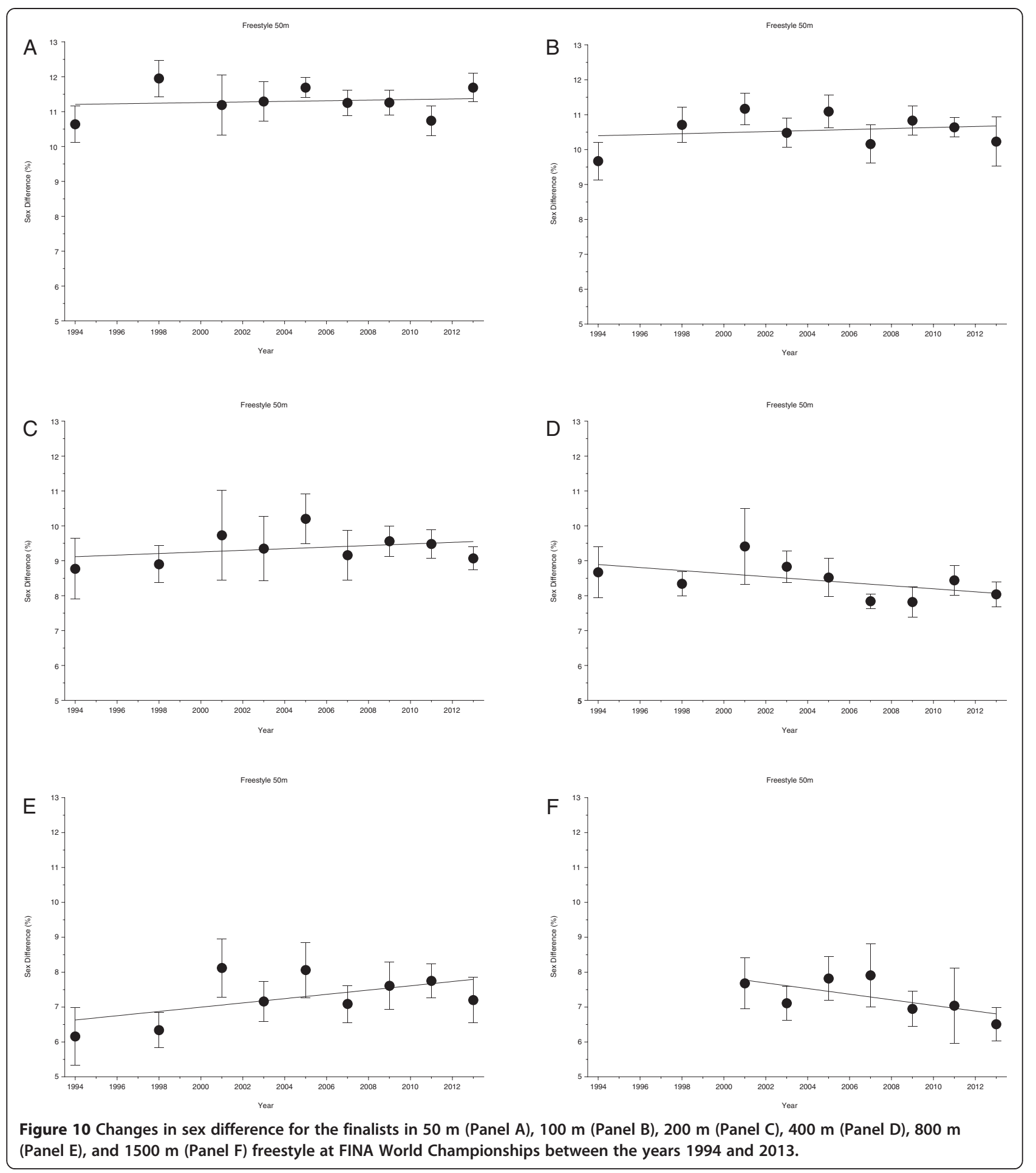

$9.92 \pm 1.48 \%$ to $8.51 \pm 0.45 \%$, respectively (Table 8 ). In $100 \mathrm{~m}$ backstroke, a non-linear increase (i.e. polynomial $2^{\text {nd }}$ degree) from $9.58 \pm 0.69 \%$ to $10.14 \pm 0.34 \%$ can be reported. For all other disciplines, the sex difference remained stable (Table 7). In Figure 12 (i.e. $50 \mathrm{~m}, 100 \mathrm{~m}$, $200 \mathrm{~m}, 400 \mathrm{~m}$ and $800 \mathrm{~m}$ freestyle) and Figure 13 (i.e. $100 \mathrm{~m}$ breaststroke, $200 \mathrm{~m}$ breaststroke, $100 \mathrm{~m}$ backstroke,
200 m backstroke, 100 m butterfly, 200 m butterfly, 200 m individual medley and $400 \mathrm{~m}$ individual medley), changes in sex difference for the world champions between 1994 and 2013 are depicted. In contrast to the finalists, no significant change in sex difference for both, female and male world champions, could be detected in any of the investigated disciplines (Table 9). 

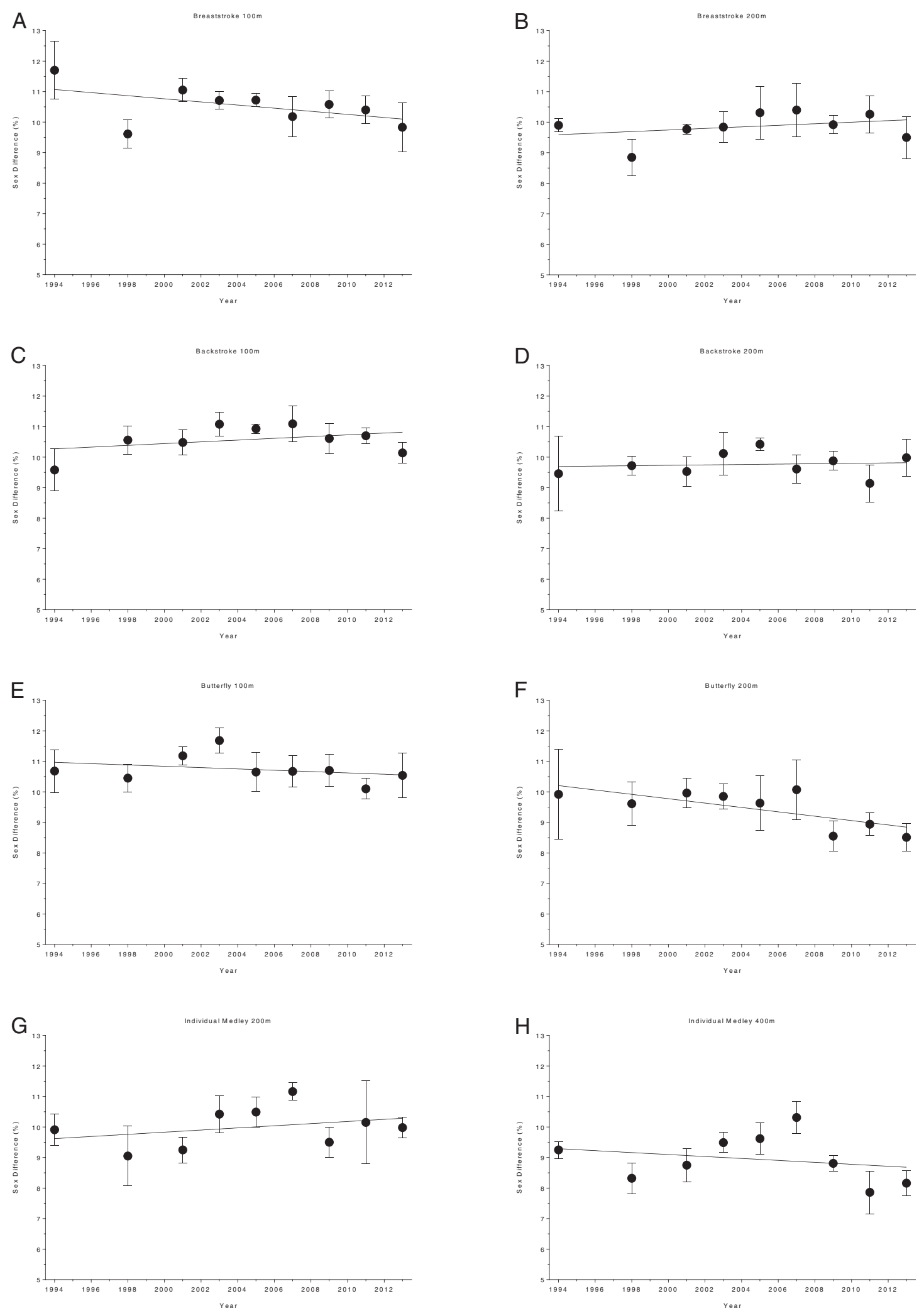

Figure 11 Changes in sex difference for the finalists in $100 \mathrm{~m}$ breaststroke (Panel A), $200 \mathrm{~m}$ breaststroke (Panel B), $100 \mathrm{~m}$ backstroke (Panel C), $200 \mathrm{~m}$ backstroke (Panel D), $100 \mathrm{~m}$ butterfly (Panel E), $200 \mathrm{~m}$ butterfly (Panel F), $200 \mathrm{~m}$ individual medley (Panel G) and $400 \mathrm{~m}$ individual medley (Panel H) at FINA World Championships between the years 1994 and 2013. 
Table 7 Multi-level regression analysis for changes in sex difference in swimming speed for finalists in the FINA World Championships in freestyle, breaststroke, backstroke, butterfly and individual medley with correction for multiple participations

\begin{tabular}{cccccc}
\hline & $\boldsymbol{\beta}$ & SE $(\boldsymbol{\beta})$ & Stand. $\boldsymbol{\beta}$ & $\mathbf{T}$ & $\boldsymbol{p}$ \\
\hline $50 \mathrm{~m}$ freestyle & 0.005 & 0.048 & 0.056 & 0.112 & 0.916 \\
$100 \mathrm{~m}$ freestyle & 0.016 & 0.020 & 0.362 & 0.777 & 0.48 \\
$200 \mathrm{~m}$ freestyle & 0.023 & 0.063 & 0.181 & 0.367 & 0.732 \\
$400 \mathrm{~m}$ freestyle & 0.007 & 0.052 & 0.071 & 0.142 & 0.89 \\
$800 \mathrm{~m}$ freestyle & -0.090 & 0.045 & -0.705 & -1.988 & 0.11 \\
$100 \mathrm{~m}$ breaststroke & -0.051 & 0.015 & -0.375 & -3.384 & 0.00 \\
$200 \mathrm{~m}$ breaststroke & 0.025 & 0.014 & 0.209 & 1.785 & 0.079 \\
100 m backstroke & 0.029 & 0.012 & 0.271 & 2.356 & 0.02 \\
$200 \mathrm{~m}$ backstroke & 0.006 & 0.014 & 0.055 & 0.460 & 0.647 \\
100 m butterfly & -0.003 & 0.021 & -0.025 & -0.168 & 0.867 \\
200 m butterfly & 0.028 & 0.012 & 0.325 & 2.333 & 0.02 \\
200 m individual medley & 0.035 & 0.018 & 0.230 & 1.978 & 0.05 \\
400 m individual medley & -0.033 & 0.017 & -0.221 & -1.884 & 0.064 \\
\hline
\end{tabular}

Changes in sex differences over the years in the Olympic Games

The changes in sex difference for the finalists in the Olympic Games are given in Figure 14 (i.e. 50 m, 100 m, $200 \mathrm{~m}, 400 \mathrm{~m}$ and $800 \mathrm{~m}$ freestyle) and Figure 15 (i.e. $100 \mathrm{~m}$ breaststroke, $200 \mathrm{~m}$ breaststroke, $100 \mathrm{~m}$ backstroke, $200 \mathrm{~m}$ backstroke, $100 \mathrm{~m}$ butterfly, $200 \mathrm{~m}$ butterfly, $200 \mathrm{~m}$ individual medley and $400 \mathrm{~m}$ individual medley). In $100 \mathrm{~m}$ backstroke, $400 \mathrm{~m}$ freestyle and $800 \mathrm{~m}$ freestyle, the sex difference decreased linearly during the analyzed time period, from $10.82 \pm 0.47 \%$ to $10.10 \pm 0.5 \%$, from $9.43 \pm 0.41 \%$ to $7.63 \pm 0.61 \%$ and from $6.53 \pm 0.51 \%$ to $5.84 \pm 0.31 \%$, respectively (Table 10 ). However, a linear increase from $9.13 \pm 0.8 \%$ to $9.44 \pm 0.35 \%$ can be reported for $200 \mathrm{~m}$ butterfly (Table 11). Changes in sex difference for the world champions between 1992 and 2012 in $50 \mathrm{~m}$, $100 \mathrm{~m}, 200 \mathrm{~m}, 400 \mathrm{~m}$ and $800 \mathrm{~m}$ freestyle are depicted in Figure 16 whereas Figure 17 shows the changes in sex difference for $100 \mathrm{~m}$ breaststroke, $200 \mathrm{~m}$ breaststroke, $100 \mathrm{~m}$ backstroke, $200 \mathrm{~m}$ backstroke, $100 \mathrm{~m}$ butterfly, $200 \mathrm{~m}$ butterfly, $200 \mathrm{~m}$ individual medley and $400 \mathrm{~m}$ individual medley. In contrast to the finalists, no significant change in sex difference for both, female and male Olympic Champions, could be detected in any of the investigated disciplines (Table 12).

\section{Discussion}

The aim of this study was to examine the trends in swimming speed and the changes in sex differences in all swimming disciplines held at the Olympic Games and FINA World Championships between 1992 and 2013. We hypothesized that (i) swimming speed would increase
Table 8 Change in sex difference over time for the finalists in the FINA World Championships

\begin{tabular}{|c|c|}
\hline \multicolumn{2}{|c|}{ Sex difference (\%) } \\
\hline 1994 & 2013 \\
\hline \multicolumn{2}{|c|}{$50 \mathrm{~m}$ freestyle } \\
\hline $10.64 \pm 0.52$ & $11.69 \pm 0.41$ \\
\hline \multicolumn{2}{|c|}{$100 \mathrm{~m}$ freestyle } \\
\hline $9.67 \pm 0.54$ & $10.23 \pm 0.70$ \\
\hline \multicolumn{2}{|c|}{$200 \mathrm{~m}$ freestyle } \\
\hline $8.77 \pm 0.87$ & $9.07 \pm .033$ \\
\hline \multicolumn{2}{|c|}{$400 \mathrm{~m}$ freestyle } \\
\hline $8.67 \pm 0.73$ & $8.04 \pm 0.36$ \\
\hline \multicolumn{2}{|c|}{$800 \mathrm{~m}$ freestyle } \\
\hline $6.16 \pm 0.83$ & $7.20 \pm 0.65$ \\
\hline \multicolumn{2}{|c|}{ 1,500 m freestyle } \\
\hline $7.68 \pm 0.73$ & $6.51 \pm 0.48$ \\
\hline \multicolumn{2}{|c|}{$100 \mathrm{~m}$ breaststroke } \\
\hline $11.70 \pm 0.95$ & $9.83 \pm 0.80$ \\
\hline \multicolumn{2}{|c|}{$200 \mathrm{~m}$ breaststroke } \\
\hline $9.90 \pm 0.22$ & $9.50 \pm 0.69$ \\
\hline \multicolumn{2}{|c|}{$100 \mathrm{~m}$ backstroke } \\
\hline $9.58 \pm 0.69$ & $10.14 \pm 0.34$ \\
\hline \multicolumn{2}{|c|}{$200 \mathrm{~m}$ backstrocke } \\
\hline $9.46 \pm 1.23$ & $9.98 \pm .060$ \\
\hline \multicolumn{2}{|c|}{100 m butterfly } \\
\hline $10.68 \pm 0.70$ & $10.54 \pm 0.74$ \\
\hline \multicolumn{2}{|c|}{200 m butterfly } \\
\hline $9.92 \pm 1.48$ & $8.51 \pm 0.45$ \\
\hline \multicolumn{2}{|c|}{$200 \mathrm{~m}$ individual medley } \\
\hline $9.91 \pm 0.52$ & $9.98 \pm 0.34$ \\
\hline \multicolumn{2}{|c|}{$400 \mathrm{~m}$ individual medley } \\
\hline $9.25 \pm 0.28$ & $8.16 \pm 0.41$ \\
\hline
\end{tabular}

Note: $* \mathrm{p}<0.05$.

across the years, (ii) the sex difference would remain unchanged in the disciplines freestyle, breaststroke, backstroke, butterfly and individual medley across all race distances and (iii) the sex difference would decrease with increasing race distance. The main findings were $(i)$ a linear increase in swimming speed of the overall top eight finalists at the Olympic Games and FINA World Championships, (ii) the fastest female swimmers increased their swimming speed rather at longer race distances (i.e. $800 \mathrm{~m}$ freestyle, 1,500 m freestyle, $200 \mathrm{~m}$ butterfly, $400 \mathrm{~m}$ individual medley), whereas the fastest male swimmers increased it rather at shorter race distances (i.e. $100 \mathrm{~m}$ freestyle, $200 \mathrm{~m}$ freestyle, $100 \mathrm{~m}$ butterfly, $100 \mathrm{~m}$ breaststroke), (iii) an unchanged sex difference in terms of swimming speed for Olympic and world champions, (iv) 


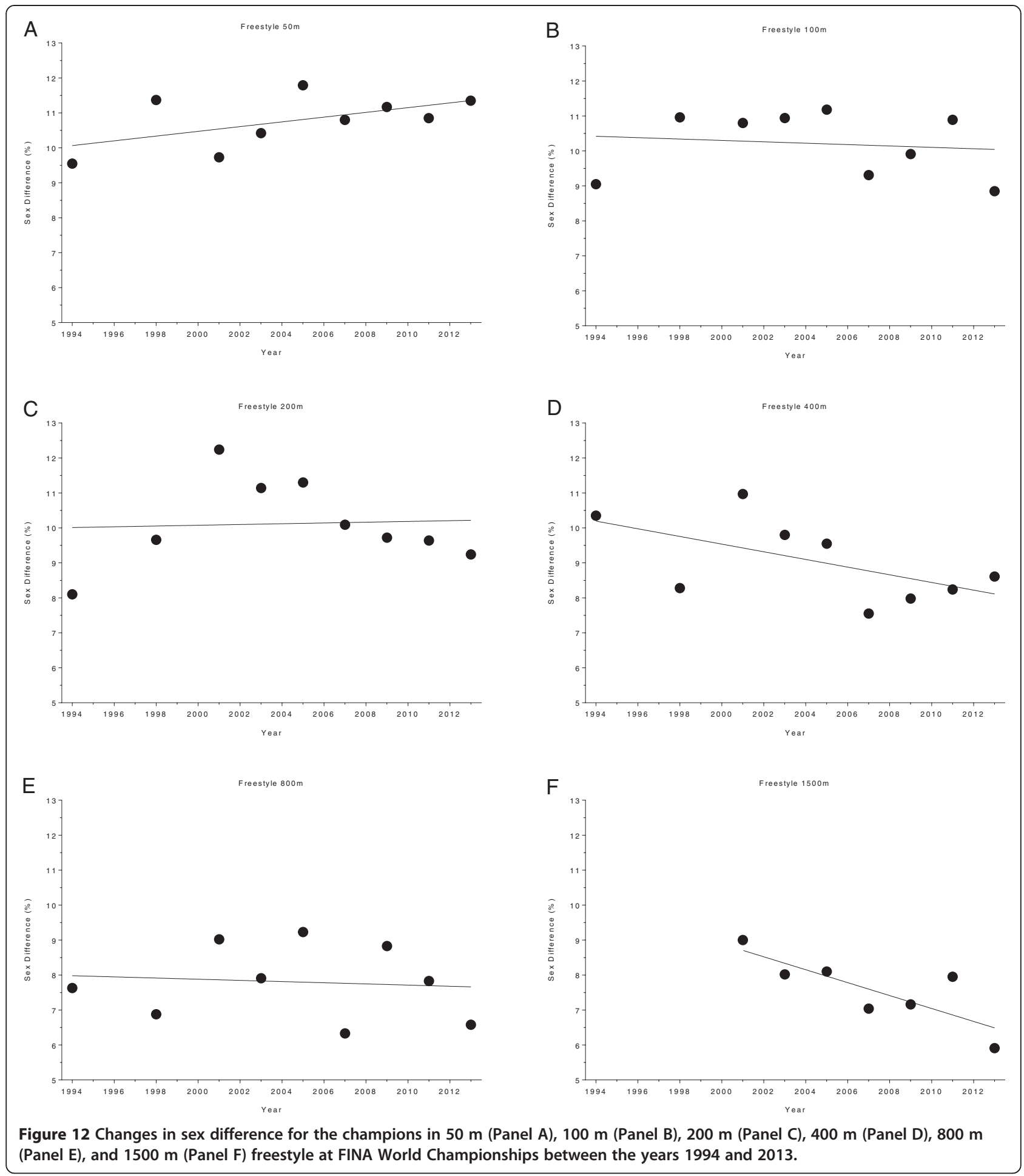

linear changes of sex differences concerning the swimming speed of all finalists, with the exception of a nonlinear increase for the finalists in $100 \mathrm{~m}$ backstroke at FINA World Championships, and ( $v$ ) for both, the finalists and champions at the Olympic Games and FINA World Championships, the sex difference was highest in the shortest race distances and lowest in the longest race distances.

\section{Increase in swimming speeds over the years}

Between 1992 and 2013, the swimming speeds of the top eight women and men competing in the finals at the 

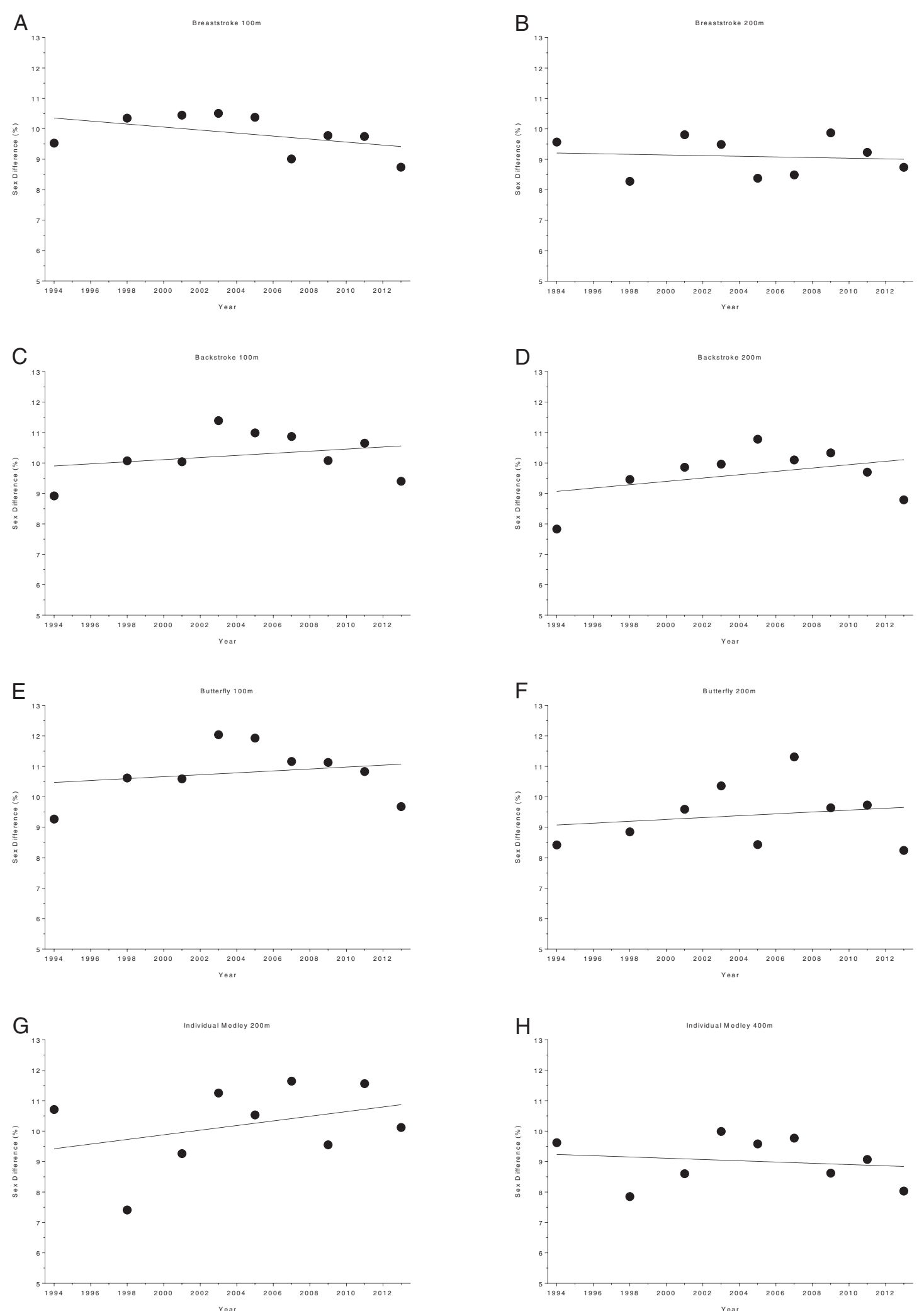

Figure 13 Changes in sex difference for the champions in $100 \mathrm{~m}$ breaststroke (Panel A), $200 \mathrm{~m}$ breaststroke (Panel B), $100 \mathrm{~m}$ backstroke (Panel C), $200 \mathrm{~m}$ backstroke (Panel D), $100 \mathrm{~m}$ butterfly (Panel E), $200 \mathrm{~m}$ butterfly (Panel F), $200 \mathrm{~m}$ individual medley (Panel G) and $400 \mathrm{~m}$ individual medley (Panel H) at FINA World Championships between the years 1994 and 2013. 
Table 9 Multi-level regression analysis for changes in sex difference in swimming speed for the world champions in freestyle, breaststroke, backstroke, butterfly and individual medley with correction for multiple participations

\begin{tabular}{cccccc}
\hline & $\boldsymbol{\beta}$ & SE $(\boldsymbol{\beta})$ & Stand. $\boldsymbol{\beta}$ & $\mathbf{T}$ & $\boldsymbol{p}$ \\
\hline $50 \mathrm{~m}$ freestyle & 0.068 & 0.038 & 0.555 & 1.767 & 0.121 \\
$100 \mathrm{~m}$ freestyle & -0.020 & 0.056 & -0.132 & -0.353 & 0.735 \\
$200 \mathrm{~m}$ freestyle & 0.011 & 0.076 & 0.054 & 0.144 & 0.889 \\
$400 \mathrm{~m}$ freestyle & -0.110 & 0.058 & -0.580 & -1.883 & 0.102 \\
$800 \mathrm{~m}$ freestyle & -0.017 & 0.065 & -0.097 & -0.259 & 0.803 \\
$100 \mathrm{~m}$ breaststroke & -0.049 & 0.035 & -0.471 & -1.413 & 0.200 \\
$200 \mathrm{~m}$ breaststroke & -0.011 & 0.038 & -0.106 & -0.281 & 0.787 \\
$100 \mathrm{~m}$ backstroke & 0.035 & 0.046 & 0.272 & 0.749 & 0.478 \\
$200 \mathrm{~m}$ backstroke & 0.055 & 0.049 & 0.388 & 1.113 & 0.302 \\
$100 \mathrm{~m}$ butterfly & 0.032 & 0.055 & 0.214 & 0.579 & 0.581 \\
200 m butterfly & 0.031 & 0.061 & 0.186 & 0.501 & 0.632 \\
$200 \mathrm{~m}$ individual medley & 0.076 & 0.077 & 0.351 & 0.993 & 0.354 \\
$400 \mathrm{~m}$ individual medley & -0.021 & 0.047 & -0.166 & -0.444 & 0.670 \\
\hline
\end{tabular}

Olympic Games and FINA World Championships increased linearly. Several studies concerning performance evolution in swimming sports have been conducted over the last decade $[4-6,12,23]$. Factors explaining this development include technological progress such as more effective 'antiwave' lane ropes or new drag-reducing swim suits as well as the swimmer's physiological and psychological skills due to better training conditions [4-6]. The present outcome supports these results. The fact that not even the beginning of a plateauing phase became apparent suggests that the observed linear improvement will continue in the next years. However, the time period analyzed might be too short to make long-term predictions regarding linear or non-linear trends. Nevertheless, our findings contradict the results of a preceding study which showed that swimming speeds reached a plateau phase beyond the 1970s [2].

Furthermore, the results differ from the reports in Vogt et al. [12], where performances of elite open-water swimmers at the $10 \mathrm{~km}$ FINA competitions from 2008 to 2012 were analyzed, and the performance of the top ten female swimmers remained stable, whereas it decreased for the top ten male swimmers during this period of time. Zingg et al. [23] analyzed the differences between $5 \mathrm{~km}, 10 \mathrm{~km} 25 \mathrm{~km}$ races from 2000 to 2012 . They showed that swimming performance of the top ten female athletes improved in $10 \mathrm{~km}$ but decreased in $5 \mathrm{~km}$ and $25 \mathrm{~km}$. The top ten male athletes' swimming performance decreased significantly in $5 \mathrm{~km}$ competitions and remained unchanged in $10 \mathrm{~km}$ and $25 \mathrm{~km}$ [23]. One reason for the discrepancy between these results and the outcomes presented in this study could be the observed period of time. While this study implicated swimmers' competition results over a period of 20 years, others focused on shorter durations [12,23]. Therefore, a possible alteration could have been too slight to be detected when a shorter time period was analyzed.

For annual female finalists, swimming speed improved rather at longer race distances (i.e. $800 \mathrm{~m}$ freestyle, $1,500 \mathrm{~m}$ freestyle, $200 \mathrm{~m}$ butterfly, $400 \mathrm{~m}$ individual medley). For annual male finalists, swimming speed increased rather at shorter race distances (i.e. $100 \mathrm{~m}$ freestyle, $200 \mathrm{~m}$ freestyle, $100 \mathrm{~m}$ butterfly, $100 \mathrm{~m}$ breaststroke). Nevill et al. [2] investigated the evolution of world records in $100 \mathrm{~m}$, $200 \mathrm{~m}, 400 \mathrm{~m}$ and $800 \mathrm{~m}$ freestyle from 1957 to 2006 . Both female and male athletes were able to improve their swimming speed in the 1960s and 1970s whereas swimming speeds seemed to plateau between the 1980s and 1990s. This correlates with the findings in Vogt et al. [12] and Zingg et al. [23]. In both studies, the swimming speed for the fastest female and male athletes remained unchanged across the years. The only exception was stated by Zingg et al. [23] where a swimming speed enhancement for men in $10 \mathrm{~km}$ competitions was reported. One the one hand, the present findings support these results since swimming speed remained unchanged in roughly half of the analyzed disciplines, distances and races. On the other hand, this study is the first that reports an increase in swimming speed in shorter race distances (i.e. $100 \mathrm{~m}$ freestyle, $200 \mathrm{~m}$ freestyle, $100 \mathrm{~m}$ butterfly, $100 \mathrm{~m}$ breaststroke) for men and longer race distances (i.e. $800 \mathrm{~m}$ freestyle, $1,500 \mathrm{~m}$ freestyle, $200 \mathrm{~m}$ butterfly, $400 \mathrm{~m}$ individual medley) for women, respectively. A potential explanation for these disparate findings might be that in contrast to the studies of Vogt et al. [12] and Zingg et al. [23] enhancements like deeper pools and more effective 'antiwave' lane ropes were introduced while the environmental situation remained unchanged in open-water competitions. Regarding the findings from Nevill et al. [2], a potential differentiator could be that age as well as multiple participations were not considered. However, in this study all swimming speed results are corrected for multiple participation and age of athletes.

\section{Changes in sex differences over the years}

A further important finding was that the sex difference between the female and male champions at the Olympic Games and FINA World Championships remained stable during the last 20 years. Therefore it seems very likely that the top women will never outperform the top men. However, referring to the finalists at FINA World Championships, the sex difference decreased linearly in $100 \mathrm{~m}$ breaststroke and $200 \mathrm{~m}$ butterfly whereas it increased non-linearly in $100 \mathrm{~m}$ backstroke. Regarding finalists at the Olympic Games the sex difference decreased linearly in $100 \mathrm{~m}$ backstroke, $400 \mathrm{~m}$ freestyle 


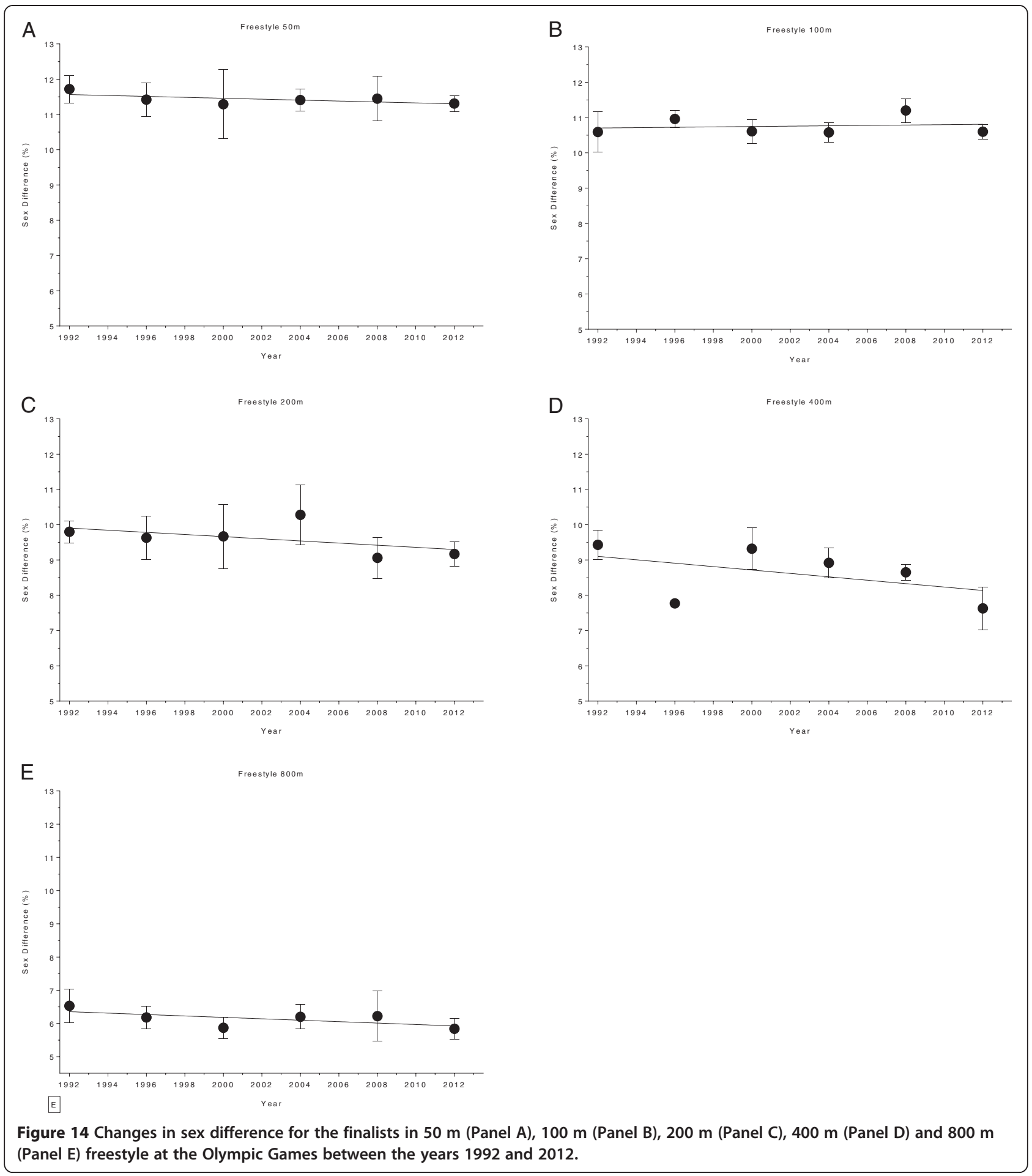

and $800 \mathrm{~m}$ freestyle whereas it increased linearly in $200 \mathrm{~m}$ butterfly.

A few authors analyzed whether the swimming speed gap between female and male athletes is narrowing down [2,9]. Nevill et al. [2] analyzed the world records from 1957 to 2006 in 100 m, $200 \mathrm{~m}$ and $400 \mathrm{~m}$ freestyle. The sex difference remained stable and is therefore in line with the findings from the present study. Buhl et al. [9] compared medley and freestyle swimming speeds of international swimmers (i.e. finalists in the FINA World Championships) between 1994 and 2011 and reported that the sex difference remained unchanged for the $200 \mathrm{~m}$ and $400 \mathrm{~m}$ medley as well as in the $200 \mathrm{~m}$ and $400 \mathrm{~m}$ freestyle races. The present findings regarding the 

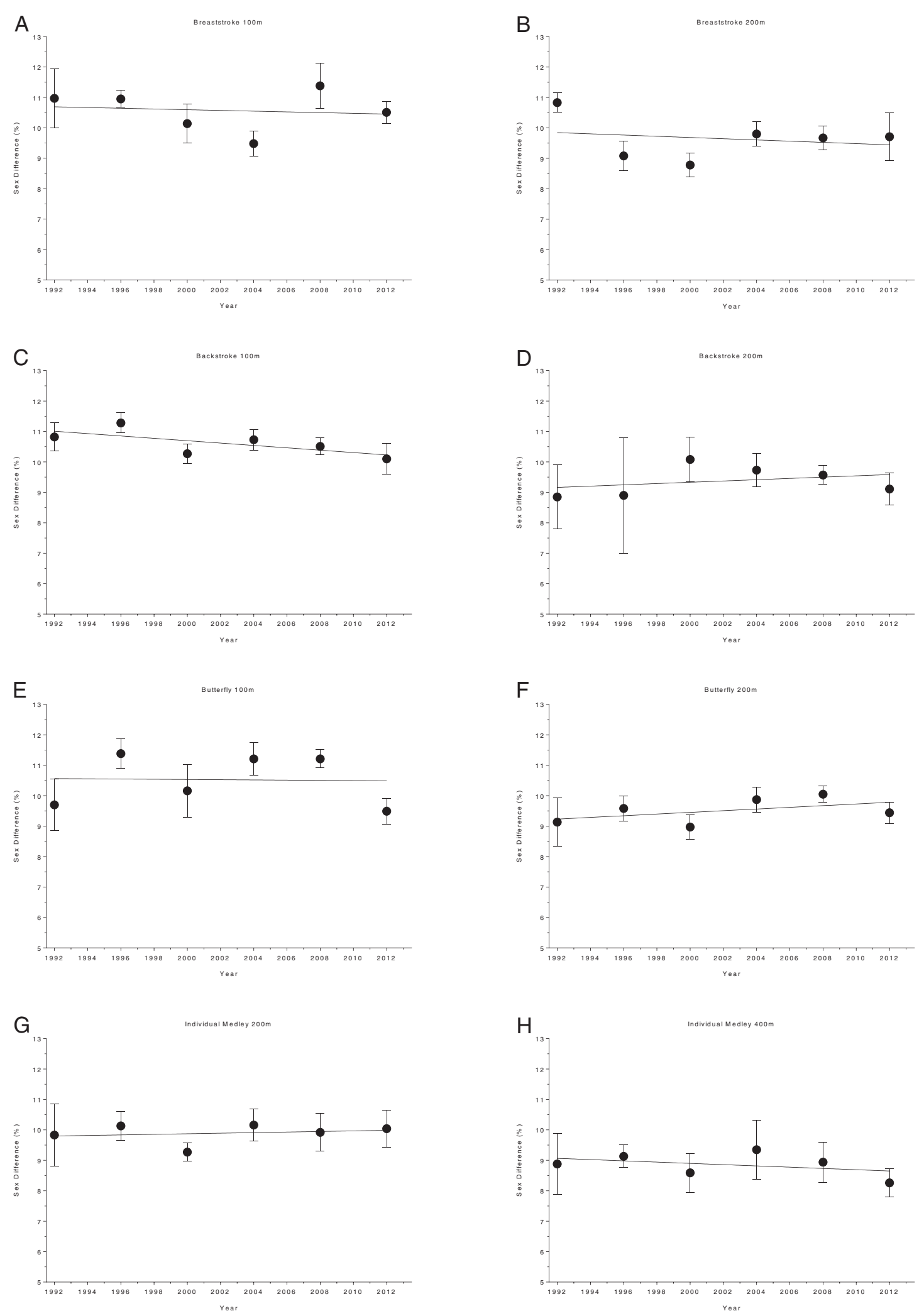

Figure 15 Changes in sex difference for the finalists in $100 \mathrm{~m}$ breaststroke (Panel A), $200 \mathrm{~m}$ breaststroke (Panel B), $100 \mathrm{~m}$ backstroke (Panel C), $200 \mathrm{~m}$ backstroke (Panel D), $100 \mathrm{~m}$ butterfly (Panel E), $200 \mathrm{~m}$ butterfly (Panel F), $200 \mathrm{~m}$ individual medley (Panel G) and $400 \mathrm{~m}$ individual medley (Panel H) at the Olympic Games between the years 1992 and 2012. 
Table 10 Multi-level regression analysis for changes in sex difference in swimming speed for finalists in the Olympic Games in freestyle, breaststroke, backstroke, butterfly and individual medley with correction for multiple participations

\begin{tabular}{cccccc}
\hline & $\boldsymbol{\beta}$ & SE $(\boldsymbol{\beta})$ & Stand. $\boldsymbol{\beta}$ & $\mathbf{T}$ & $\boldsymbol{p}$ \\
\hline $50 \mathrm{~m}$ freestyle & -0.014 & 0.012 & -0.170 & -1.171 & 0.248 \\
$100 \mathrm{~m}$ freestyle & 0.005 & 0.009 & 0.087 & 0.592 & 0.557 \\
$200 \mathrm{~m}$ freestyle & -0.030 & 0.015 & -0.284 & -2.010 & 0.050 \\
$400 \mathrm{~m}$ freestyle & -0.048 & 0.016 & -0.409 & -3.038 & 0.004 \\
$800 \mathrm{~m}$ freestyle & -0.021 & 0.010 & -0.295 & -2.098 & 0.041 \\
$100 \mathrm{~m}$ breaststroke & -0.012 & 0.018 & -0.098 & -0.668 & 0.507 \\
$200 \mathrm{~m}$ breaststroke & -0.020 & 0.017 & -0.174 & -1.198 & 0.237 \\
$100 \mathrm{~m}$ backstroke & -0.039 & 0.010 & -0.507 & -3.990 & 0.000 \\
$200 \mathrm{~m}$ backstroke & 0.021 & 0.022 & 0.140 & 0.957 & 0.344 \\
$100 \mathrm{~m}$ butterfly & -0.003 & 0.021 & -0.025 & -0.168 & 0.867 \\
$200 \mathrm{~m}$ butterfly & 0.028 & 0.012 & 0.325 & 2.333 & 0.024 \\
$200 \mathrm{~m}$ individual medley & 0.009 & 0.014 & 0.095 & 0.644 & 0.523 \\
$400 \mathrm{~m}$ individual medley & -0.021 & 0.016 & -0.187 & -1.289 & 0.204 \\
\hline
\end{tabular}

decreased sex difference in the Olympic Games and FINA World Championship finalists differ from these findings of Buhl et al. [9]. A potential explanation for this disparate finding might be that in the study from Buhl et al. [9] a linear regression and one-way analysis of variance was used whereas in this study a multi-level regression analysis with correction for multiple participations and age of athletes was applied.

This study has shown that sex difference decreased with increasing race distance. Different research studies on sex difference evolution with increasing race distance have been conducted over the last decades [7,9-11]. Tanaka and Seals [7] reported a decrease in sex difference with increasing race distance between 1991 and 1995. In detail, for freestyle swimmers the sex difference in swimming speed decreased from $19 \pm 1 \%$ for $50 \mathrm{~m}$ to $11 \pm 1 \%$ for $1,500 \mathrm{~m}$. Buhl et al. [9] compared medley and freestyle swimming speeds for national (i.e. top ten elite Swiss athletes) and international swimmers (i.e. top eight FINA World Championship athletes) between 1994 and 2011. These authors reported that the sex difference for national and international athletes in $400 \mathrm{~m}$ medley as well as freestyle was lower compared to the $200 \mathrm{~m}$ disciplines. Wolfrum et al. [10] focused on national and international breaststroke and freestyle disciplines and reported a decrease sex difference with increasing race distance. Relating to sex difference, Rüst et al. [11] also reported a decrease in sex difference with increasing race distance from $50 \mathrm{~m}$ to $800 \mathrm{~m}$ amongst Swiss elite freestyle swimmers ranked on the Swiss high score list between 2006 and 2010 . However, they reported that for $1,500 \mathrm{~m}$ freestyle, the sex difference increased compared to $800 \mathrm{~m}$
Table 11 Change in sex difference over time for the finalists in the Olympic Games

\begin{tabular}{|c|c|c|c|}
\hline \multicolumn{4}{|c|}{ Sex difference (\%) } \\
\hline 1992 & & 2012 & \\
\hline \multicolumn{4}{|c|}{$50 \mathrm{~m}$ freestyle } \\
\hline \multirow[t]{2}{*}{$11.72 \pm 0.39$} & $11.31 \pm 0.23$ & & \\
\hline & $100 r$ & & \\
\hline \multirow[t]{2}{*}{$10.59 \pm 0.57$} & $10.60 \pm 0.21$ & & \\
\hline & $200 r$ & & \\
\hline \multirow[t]{2}{*}{$9.80 \pm 0.31$} & $9.17 \pm 0.34$ & & \\
\hline & $400 r$ & & \\
\hline \multirow[t]{2}{*}{$9.43 \pm 0.41$} & $7.63 \pm 0.61$ & & * \\
\hline & $800 r$ & & \\
\hline \multirow[t]{2}{*}{$6.53 \pm 0.51$} & $5.84 \pm 0.30$ & & * \\
\hline & $100 \mathrm{~m}$ & & \\
\hline \multirow[t]{2}{*}{$10.97 \pm 0.97$} & $10.51 \pm 0.36$ & & \\
\hline & $200 \mathrm{~m}$ & & \\
\hline \multirow[t]{2}{*}{$10.83 \pm 0.32$} & $9.71 \pm 0.79$ & & \\
\hline & $100 \mathrm{~m}$ & & \\
\hline \multirow[t]{2}{*}{$10.82 \pm 0.47$} & $10.10 \pm 0.50$ & & * \\
\hline & $200 \mathrm{~m}$ & & \\
\hline \multirow[t]{2}{*}{$8.85 \pm 1.05$} & $9.11 \pm 0.53$ & & \\
\hline & $100 r$ & & \\
\hline \multirow[t]{2}{*}{$9.70 \pm 0.84$} & $9.49 \pm 0.42$ & & \\
\hline & $200 r$ & & \\
\hline \multirow[t]{2}{*}{$9.13 \pm 0.80$} & $9.44 \pm 0.35$ & & * \\
\hline & $200 \mathrm{~m}$ inc & edley & \\
\hline \multirow[t]{2}{*}{$9.83 \pm 1.02$} & $10.04 \pm 0.61$ & & \\
\hline & $400 \mathrm{~m}$ inc & edley & \\
\hline $8.88 \pm 1.0$ & $8.26 \pm 0.47$ & & \\
\hline
\end{tabular}

Note: * $p<0.05$.

freestyle. A potential explanation for this disparate finding might be that the study was based on Swiss elite freestyle swimmers only. Also the relatively short time period of about 5 years could be the differentiating factor. All these studies considered only a short period of time, but presented a gap between female and male swimming speeds, which narrows with increasing race distance. With this present study it was possible to reveal that this observation also applies when swimming speeds from over two decades are taken into account.

It seems that women have an advantage with increasing race distance and may even outperform men in long-endurance swimming competitions. The natural difference in body fat percentage might explain the decrease of sex differences with increasing race distance $[14,24,25]$. A similar explanation was provided by Etter et al. [26] and Knechtle et al. [27] reporting that the 


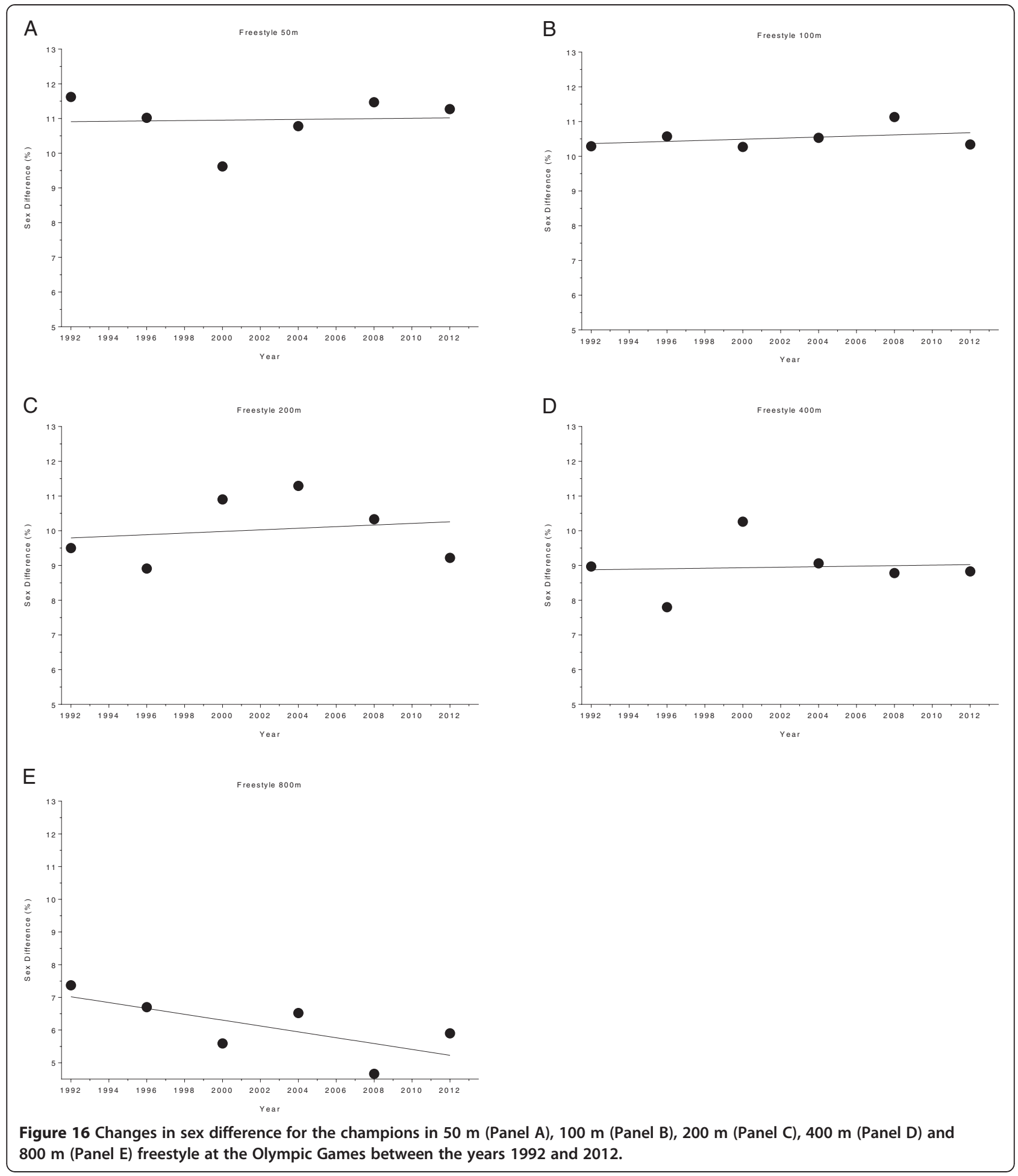

higher body fat percentage of female athletes is an advantage in open-water competitions due to better isolation against the cold water. The lower skeletal muscle mass of female athletes compared to their male counterparts was argued to be another explaining factor of the lower sex difference with increasing race distance [28].
Already in 2010, Knechtle et al. [29] reported that male ultra-endurance athletes have a higher skeletal muscle mass than female ultra-endurance athletes. Knechtle et al. investigated the skeletal muscle mass of female and male Ironman triathletes [29] and ultra-runners [30]. They reported that male triathletes had an approximately $46 \%$ 

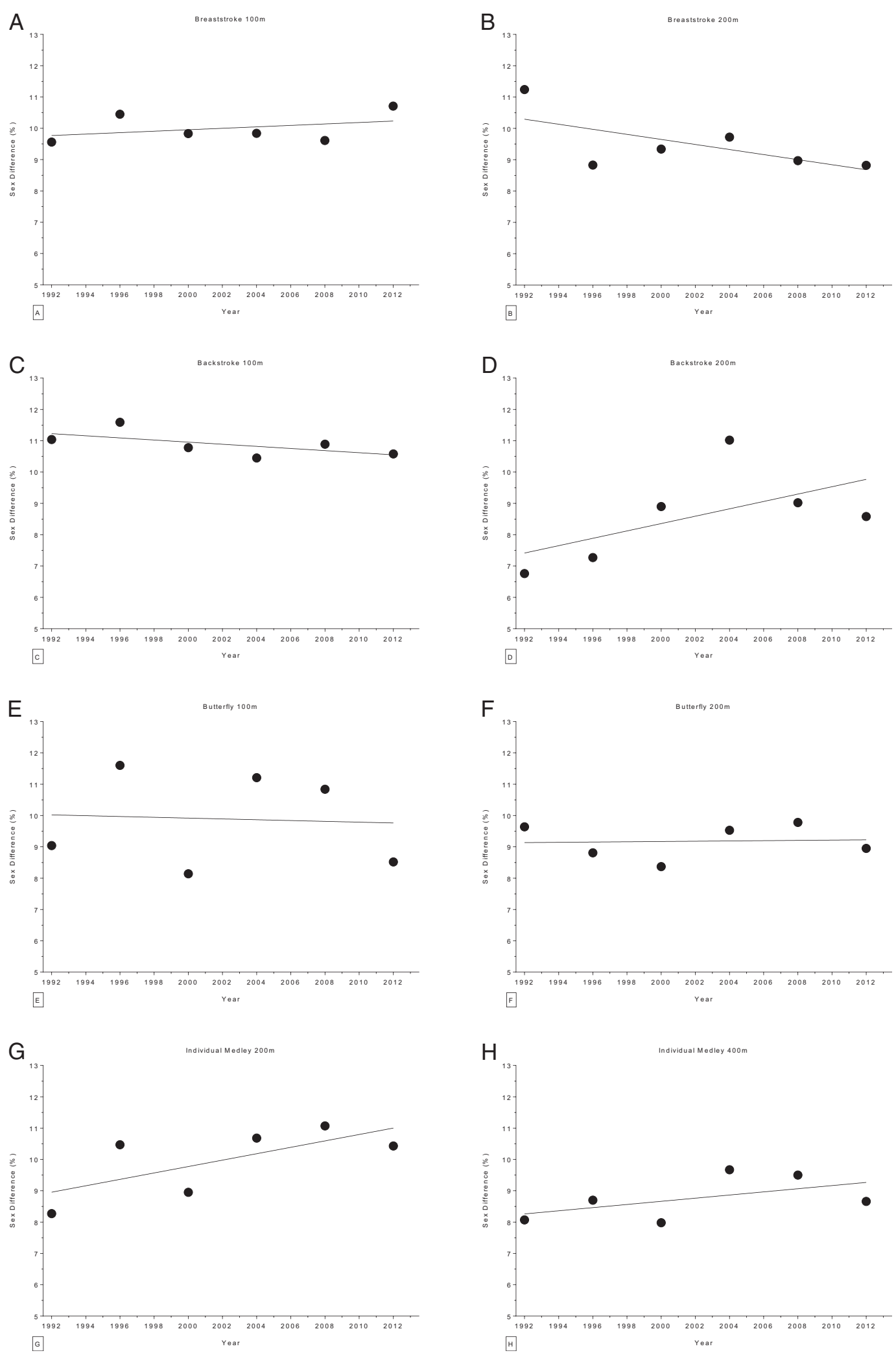

Figure 17 Changes in sex difference for the champions in $100 \mathrm{~m}$ breaststroke (Panel A), $200 \mathrm{~m}$ breaststroke (Panel B), $100 \mathrm{~m}$ backstroke (Panel C), $200 \mathrm{~m}$ backstroke (Panel D), $100 \mathrm{~m}$ butterfly (Panel E), $200 \mathrm{~m}$ butterfly (Panel F), $200 \mathrm{~m}$ individual medley (Panel G) and $400 \mathrm{~m}$ individual medley (Panel H) at the Olympic Games between the years 1992 and 2012. 


\begin{tabular}{|c|c|c|c|c|c|}
\hline & $\beta$ & SE $(\beta)$ & Stand. $\beta$ & $T$ & $p$ \\
\hline $50 \mathrm{~m}$ freestyle & 0.005 & 0.048 & 0.056 & 0.112 & 0.916 \\
\hline $100 \mathrm{~m}$ freestyle & 0.016 & 0.020 & 0.362 & 0.777 & 0.481 \\
\hline $200 \mathrm{~m}$ freestyle & 0.023 & 0.063 & 0.181 & 0.367 & 0.732 \\
\hline $400 \mathrm{~m}$ freestyle & 0.007 & 0.052 & 0.071 & 0.142 & 0.894 \\
\hline $800 \mathrm{~m}$ freestyle & -0.090 & 0.045 & -0.705 & -1.988 & 0.118 \\
\hline $100 \mathrm{~m}$ breaststroke & 0.023 & 0.029 & 0.368 & 0.792 & 0.473 \\
\hline $200 \mathrm{~m}$ breaststroke & -0.081 & 0.047 & -0.652 & -1.719 & 0.161 \\
\hline $100 \mathrm{~m}$ backstroke & -0.034 & 0.021 & -0.627 & -1.608 & 0.183 \\
\hline $200 \mathrm{~m}$ backstroke & 0.118 & 0.081 & 0.586 & 1.447 & 0.221 \\
\hline $100 \mathrm{~m}$ butterfly & -0.013 & 0.100 & -0.065 & -0.129 & 0.903 \\
\hline 200 m butterfly & 0.004 & 0.037 & 0.060 & 0.120 & 0.911 \\
\hline 200 m individual medley & 0.102 & 0.053 & 0.693 & 1.923 & 0.127 \\
\hline 400 m individual medley & 0.050 & 0.040 & 0.535 & 1.266 & 0.274 \\
\hline
\end{tabular}

higher skeletal muscle mass compared to their female counterparts. In numbers, male and female triathletes exhibited approximately $41 \mathrm{~kg}$ and $28 \mathrm{~kg}$ of skeletal muscle mass, respectively [29]. However, male ultra-runners possess with $38 \mathrm{~kg}$ an approximately $38 \%$ higher skeletal muscle mass than females, which feature $27.4 \mathrm{~kg}$ of skeletal muscle mass [30]. Overall, it seems that male athletes have an advantage regarding skeletal muscle mass. Nevertheless, Weitkunat et al. [31] showed that male openwater ultra-swimmers experience significant reduction in body mass and skeletal muscle mass. Female open-water ultra-swimmers do not seem to be a subject to this effect, as they show no significant changes with regard to these variables. Another aspect was investigated by Knechtle et al. [32-34], whereby these authors analyzed if anthropometric characteristics such as body mass, body height and length of arms have an influence on the overall swimming speed in open-water ultra-distance swimming. They found out that these characteristics did not relate to open-water ultra-distance swimming speed, except body mass index to male swimming speed. Lepers [25] and Lepers and Maffiuletti [35] reported that the underwater torque for female athletes is lower compared to male athletes. On the other hand, female athletes outperform their male colleagues in terms of mechanical efficiency.

Most of these physical factors may explain the development of the gap between female and male swimming speed. However, psychological factors that were not taken into account so far also have a high influence on swimming speed and outcome. Therefore, more studies that focus not only on physical conditions but also on an athlete's mental status would be needed to fully understand sex differences in elite athletes.

\section{Limitations}

Our study is limited since potential prediction variables such as psychological skills and emotional competencies [6] as well as more efficient training processes based on better training control [5] were not taken into account. Also the improvement in pool design and 'antiwave lane' ropes [5] as well as the new drag-reducing swimsuits [4] have not been considered. These variables, environmental as well as material improvements might have influenced race outcomes.

\section{Conclusions}

To summarize, the swimming speed for the overall top eight finalists at FINA World Championships and the Olympic Games increased linearly in all disciplines and distances. Considering men, the top annual swimmers improved it rather at shorter race distances (i.e. $100 \mathrm{~m}$ freestyle, $200 \mathrm{~m}$ freestyle, $100 \mathrm{~m}$ butterfly, $100 \mathrm{~m}$ breaststroke), whereas the top annual female swimmers improved their swimming speed rather at longer race distances (i.e. $800 \mathrm{~m}$ freestyle, $1,500 \mathrm{~m}$ freestyle, $200 \mathrm{~m}$ butterfly, $400 \mathrm{~m}$ individual medley). The sex difference remained unchanged in Olympic and FINA World Champions between 1992 and 2013. However, the finalists and champions at the Olympic Games and FINA World Championships decreased the sex difference with increasing race distance. Further studies would be needed to examine how psychological skills, emotional competencies, more efficient training processes based on better training control, improved pool design and 'antiwave lane' ropes as well as the new drag-reducing swimsuits influence swimming speed and sex difference. Nevertheless, it seems unlikely that female elite athletes will overtop their male counterparts in any of the indoor swimming disciplines held at FINA World Championships and the Olympic Games.

\section{Competing interests \\ The authors declare that they have no competing interest.}

\section{Authors' contributions}

SW collected the data and drafted the manuscript, CR performed the statistical analyses, TR participated in the design of the study, BK helped in collecting the data, in interpretation of the results and in drafting the manuscript. All authors read and approved the final manuscript.

\section{Acknowledgements}

The authors would like to thank all organizations who provided publicly available swimming results and therefore established the authors for creating this work. Further, we would like to give special thanks to Annina Michel (MSc. in Geography at the University of Zurich), Markus Pelnar (MSc. in Telematics at Graz University of Technology) and Stephanie Heuser (PhD Student at Science for Life Laboratory) for language corrections. 


\section{References}

1. Berthelot G, Thibault V, Tafflet M, Escolano S, El Helou N, Jouven X, Hermine O, Toussaint J: The citius end: world records progression announces the completion of a brief ultra-physiological quest. PLoS One 2008, 3:1.

2. Nevill AM, Whyte GP, Holder RL, Peyrebrunne M: Are there limits to swimming world records? Int I Sports Med 2007, 28:1012-1017.

3. Thibault V, Guillaume M, Berthelot G, Helou NE, Schaal K, Quinquis L, Nassif H, Tafflet M, Escolano S, Hermine O, Toussaint JF: Women and men in sport performance: the gender gap has not evolved since 1983. J Sports Sci Med 2010, 9:214-223.

4. Berthelot $G$, Len $S$, Hellard P: Technology and swimming: 3 steps beyond physiology. Mater Today (Kidlington) 2010, 13:46-51.

5. Colwin C: Looking back, looking ahead. In Breakthrough Swimming. Edited by McEntire C, Hawkins S, Wntworth J. Champaign (IL): Human Kinetics; 2002:217-228.

6. Smith $D$, Norris $S$, Hogg J: Performance evaluation of swimmers: scientific tools. Sports Med 2002, 32:539-554.

7. Tanaka H, Seals DR: Age and gender interactions in physiological functional capacity: insight from swimming performance. J Appl Physiol 1997, 82:846-851.

8. Seiler S, De Koning J, Foster C: The fall and rise of the gender difference in elite anaerobic performance 1952-2006. Med Sci Sports Exerc 2007, 39:534-540.

9. Buhl C, Knechtle B, Rüst CA, Rosemann T, Lepers R: A comparison of medley and freestyle performance for national and international swimmers between 1994 and 2011. Open Access J Sports Med 2013, 4:79-87.

10. Wolfrum M, Knechtle B, Rüst CA, Rosemann T, Lepers R: Sex-related differences and age of peak performance in breaststroke versus freestyle swimming. BMC Sports Sci Med Rehabil 2013, 5:29.

11. Rüst $C A$, Knechtle $B$, Rosemann $T$ : Women achieve peak freestyle swim speed at earlier ages than men. Open Access J Sports Med 2012, 3:189-199.

12. Vogt P, Rüst CA, Rosemann T, Lepers R, Knechtle B: Analysis of $10 \mathrm{~km}$ swimming performance of elite male and female open-water swimmers. Springerplus 2013, 2:603.

13. Eichenberger $E$, Knechtle B, Rüst CA, Knechtle $P$, Lepers R, Rosemann T: No gender difference in peak performance in ultra-endurance swimming performance - analysis of the 'Zurich 12-h Swim' from 1996 to 2010. Chin J Physiol 2012, 55:346-351

14. Eichenberger E, Knechtle B, Knechtle P, Rüst CA, Rosemann T, Lepers R, Senn O: Sex difference in open-water ultra-swim performance in the longest freshwater lake swim in Europe. J Strength Cond Res 2013, 27:1362-1369.

15. Knechtle B, Rosemann $T$, Lepers $R$, Rüst CA: Women outperform men in ultra-distance swimming - the 'Manhattan Island Marathon Swim' from 1983 to 2013. Int I Sports Physiol Perform 2014. [Epub ahead of print].

16. Rüst CA, Lepers R, Rosemann T, Knechtle B: Will women soon outperform men in open-water ultra distance swimming in the 'Maratona del Golfo Capri-Napoli'? Springerplus 2014, 3:86.

17. Rüst $C A$, Knechtle $B$, Rosemann $T$, Lepers $R$ : Women reduced the sex difference in open-water ultra-distance swimming: La Traversée Internationale du Lac St-Jean, 1955-2012. Appl Physiol Nutr Metab 2014 39:270-273.

18. Zingg MA, Rüst CA, Rosemann T, Lepers R, Knechtle B: Analysis of sex differences in open-water ultra-distance swimming performances in the FINA World Cup races in $5 \mathrm{~km}, 10 \mathrm{~km}$ and $25 \mathrm{~km}$ from 2000 to 2012. BMC Sports Sci Med Rehabil 2014, 6:7.

19. FINA - Fédération Internationale de Natation. website http://www.fina.org/. Accessed 20 Nov 2013.

20. OMEGA - Offical timekeeper: 15th FINA World Championships. website http:// www.omegatiming.com. Accessed 20 Nov 2013.

21. SWIMRANKINGS - Worldwide simming rankings. website http://www. swimrankings.net. Accessed 20 Nov 2013.

22. Reinboud W: Linear models can't keep up with sport gender gap. Nature 2004, 432:147.

23. Zingg MA, Rüst CA, Rosemann T, Lepers R, Knechtle B: Analysis of swimming performance in FINA World Cup long-distance open water races. Extrem Physiol Med 2014, 3:2.

24. Lavoie JM, Montpetit RR: Applied physiology of swimming. Sports Med 1986, 3:165-189

25. Lepers R: Analysis of Hawaii ironman performances in elite triathletes from 1981 to 2007. Med Sci Sports Exerc 2008, 40:1828-1834.
26. Etter F, Knechtle B, Bukowski A, Rüst CA, Rosemann T, Lepers R, Senn O: Age and gender interactions in short distance triathlon performance. J Sports Sci 2013, 31:996-1006.

27. Knechtle B, Christinger N, Kohler G, Knechtle P, Rosemann T: Swimming in ice cold water. Ir J Med Sci 2009, 178:507-511.

28. Knechtle B, Knechtle $P$, Lepers R: Participation and performance trends in ultra-triathlons from 1985 to 2009. Scand J Med Sci Sports 2011, 21:82-90.

29. Knechtle B, Wirth A, Baumann B, Knechtle P, Kohler G, Rosemann T, Senn O: An ironman triathlon does not lead to a change in body mass in female triathletes. Res Sports Med 2010, 18:115-126.

30. Knechtle B, Senn O, Imoberdorf R, Joleska I, Wirth A, Knechtle P, Rosemann T: Maintained total body water content and serum sodium concentrations despite body mass loss in female ultra-runners drinking ad libitum during a $100 \mathrm{~km}$ race. Asia Pac J Clin Nutr 2010, 19:83-90.

31. Weitkunat $T$, Knechtle B, Knechtle P, Rüst CA, Rosemann T: Higher prevalence of exercise-associated hyponatremia in female than in male open-water ultra-endurance swimmers: the "Marathon-Swim" in Lake Zurich. Eur J Appl Physiol 2012, 112:1095-1106.

32. Knechtle B, Knechtle P, Kohler G: No correlation of anthropometry and race performance in ultra-endurance swimmers at a 12-hours-swim. Anthropol Anz 2008, 66:73-79.

33. Knechtle B, Baumann B, Knechtle P, Rosemann T: Speed during training and anthropometric measures in relation to race performance by male and female open-water ultra-endurance swimmers. Percept Mot Skills 2010, 111:463-474.

34. Knechtle B, Baumann B, Knechtle P, Rosemann T: What influences race performance in male open-water ultra-endurance swimmers: anthropometry or training? Human Mov Sci 2010, 11:5-10,

35. Lepers R, Maffiuletti NA: Age and gender interactions in ultraendurance performance: insight from the triathlon. Med Sci Sports Exerc 2011, 43:134-139.

doi:10.1186/2052-1847-6-25

Cite this article as: Wild et al: Changes in sex difference in swimming speed in finalists at FINA World Championships and the Olympic Games from 1992 to 2013. BMC Sports Science, Medicine, and Rehabilitation 2014 6:25.

\section{Submit your next manuscript to BioMed Central and take full advantage of:}

- Convenient online submission

- Thorough peer review

- No space constraints or color figure charges

- Immediate publication on acceptance

- Inclusion in PubMed, CAS, Scopus and Google Scholar

- Research which is freely available for redistribution 